\title{
In vitro and in vivo evaluation of folate receptor-targeting amphiphilic copolymer- modified liposomes loaded with docetaxel
}

This article was published in the following Dove Press journal:

International Journal of Nanomedicine

8 June 2011

Number of times this article has been viewed

\section{Xiang $\mathrm{Li}^{\prime}$ \\ Xin Tian ${ }^{2}$ \\ Jing Zhang ${ }^{3}$ \\ Xu Zhao' \\ Xiaohui Chen' \\ Youhong Jiang ${ }^{2}$ \\ Dongkai Wang' \\ Weisan Pan'}

'Department of Pharmaceutics, School of Pharmacy, Shenyang Pharmaceutical University, Shenyang; ${ }^{2}$ The Second Laboratory of Cancer Research Institution, The First Hospital of China Medical University, Shenyang; ${ }^{3}$ Key Laboratory of Modern Preparation of TCM, Ministry of Education, Jiangxi University of Traditional Chinese Medicine, Nanchang, China
Correspondence: Weisan Pan and Dongkai Wang

PO Box 57, Shenyang Pharmaceutical

University, 103 Wenhua Road, Shenyang

I I00 I6, China

Tel +862423986310

Fax +862423986310

Email edward.st.lee@gmail.com
Background: The purpose of this study was to develop folate-poly (PEG-cyanoacrylateco-cholesteryl cyanoacrylate) (FA-PEG-PCHL)-modified freeze-dried liposomes for targeted chemotherapy using docetaxel as a model drug.

Methods: FA-PEG-PCHL was synthesized and its cytotoxicity was evaluated by CCK-8 assay in L929. Docetaxel-loaded liposomes modified by FA-PEG-PCHL were prepared by an organic solvent injection method and lyophilized to obtain freeze-dried FA-PEG-PCHLdocetaxel liposomes (FA-PDCT-L). Two carcinoma cell lines (MCF-7 and A-549 cells) were cultured with docetaxel solution, conventional docetaxel-loaded liposomes, or FA-PDCT-L, and the cytotoxicity and apoptosis was evaluated for each preparation. The uptake of the docetaxel preparations into MCF-7 cells was studied by confocal laser scanning microscopy. Liquid chromatography-mass spectrometry was used to study the pharmacokinetics and tissue distribution characteristics of the preparations.

Results: The existence of an enlarged fixed aqueous layer on the surface of the liposomes was affirmed by zeta potential analysis. The entrapment efficiency and particle size distribution were almost the same as those of docetaxel-loaded liposomes. The drug release profile showed that the release rate was faster at higher molecular weight of the polymer. Compared with docetaxel solution and docetaxel-loaded liposomes, FA-PDCT-L demonstrated the strongest cytotoxicity against two carcinoma cell lines, the greatest intracellular uptake especially in the nucleus, as well as the most powerful apoptotic efficacy. In pharmacokinetic studies, the area under the plasma concentration-time curve of FA-PDCT-L was increased 3.82 and 6.23 times in comparison with the values for the docetaxel-loaded liposomes and docetaxel solution, respectively. Meanwhile, a lower concentration of docetaxel was observed for FA-PDCT-L in the liver and spleen, and a significantly higher concentration of FA-PDCT-L in tumors suggested that the presence of FA-PEG-PCHL on the liposomes resulted in greater accumulation of the drug in tumor tissue.

Conclusion: Liposomes modified by FA-PEG-PCHL could be one of the promising suspensions for the delivery of antitumor drugs in cancer.

Keywords: folate-poly (PEG-cyanoacrylate-co-cholesteryl cyanoacrylate), docetaxel, freezedried liposomes, tumor targeting

\section{Introduction}

Nanotechnology has been extensively exploited to improve conventional cancer therapy recently. ${ }^{1,2}$ The nanocarriers currently under intensive investigation can be divided into two categories in general, ie, polymer-based and lipid-based polymeric nanoparticles and liposomes. ${ }^{3}$ The use of polymeric nanoparticles using biodegradable polymers, such as poly (D,L-lactic acid), poly (D,L-lactic-co-glycolic acid) and poly (3-caprolactone), and 
their copolymers diblocked or multiblocked with polyethylene glycol (PEG), for drug delivery has shown promising therapeutic potential. ${ }^{4-6}$ These nanoparticles have been widely used because of their high drug-loading capacity especially for hydrophobic drugs, controlled drug release, acceptable biocompatibility, high cellular internalization, and a long circulation half-life. ${ }^{2}$ However, polymeric nanoparticles have reported moderate circulation half-lives in comparison with their liposomal counterparts, even when coated with biocompatible polymers such as PEG. ${ }^{7}$

Liposomes are spherical vesicles composed of single or multiple lipid bilayers, and have a number of appealing features, including high biocompatibility, high delivery efficiency, a favorable pharmacokinetic profile, and ease of surface modification. ${ }^{8,9}$ The performance of liposome drug delivery systems for tumor therapy could be further improved by using a ligand coupled to the surface of vesicles to achieve an active targeting effect. The selective overexpression of folate receptors in tumor cells and the high affinity of tumors for folic acid provide a unique opportunity for folic acid to be used as a targeting ligand to deliver therapeutic agents to cancer cells via folate receptor-mediated endocytosis. ${ }^{10}$ Folate-mediated targeting liposomes has been obtained by the incorporation of a small amount of folate-polyethyleneglycoldistearoyl-phosphatidyl-ethanolamine. ${ }^{11}$

In this study, we explored the potential use of a novel conjugate, folate-poly (PEG-cyanoacrylate-co-cholesteryl cyanoacrylate) (FA-PEG-PCHL) for liposome targeting by insertion into liposomal bilayers. Docetaxel is used as a model hydrophobic anticancer drug, and shows high anticancer efficacy in patients with ovarian carcinoma, lung cancer, advanced breast cancer, and head/neck cancer. ${ }^{12}$ The incorporation of PEG can prolong the residence time of liposomes in the blood, and efficient folate receptor binding and endocytosis of folate-derived liposomes can be achieved by separating folate from the liposomal surface when a PEG spacer is used, ${ }^{13}$ for the reason that folic acid has the flexibility to interact with the corresponding cell surface receptor. ${ }^{14}$ As a result, PEG was selected as the hydrophilic group to achieve a long circulation effect and better connection performance from folic acid. Meanwhile, the hydrophobic domains are formed by the poly cholesteryl cyanoacrylate moieties. We modified this block copolymer with cholesterol in order to achieve better compatibility with the lecithin bilayer. ${ }^{15}$ Cholesterol is often used to modify biomaterials hydrophobically due to its rigid and highly hydrophobic sterol skeleton. ${ }^{16,17}$

The two main goals of the present work were, firstly, to report a novel amphiphilic copolymer, ie, FA-PEG-PCHL, with a series of molecular weights (4374-12394 Da) and low cytotoxicity, and, secondly, to investigate the characteristics, in vitro cytotoxicity, intracellular uptake, apoptotic effect, in vivo pharmacokinetics, and tissue distribution of FA-PEGPCHL- modified, freeze-dried docetaxel-loaded liposomes (FA-PDCT-L).

\section{Materials and methods Materials}

$\alpha$-Amino- $\omega$-hydroxy-polyethyleneglycol $\left(\mathrm{NH}_{2}-\mathrm{PEG}-\mathrm{OH}\right.$, molecular weights $2 \mathrm{kDa}, 4 \mathrm{kDa}$, and $10 \mathrm{kDa}$ ) was purchased from Alfa Aesar (Heysham, UK). Dicyclohexylcarbodiimide, cyanoacetic acid, cholesterol, and 1, 4-(dimethylamino) pyridine (DMAP) were purchased from Acros Organics (Geel, Belgium). Cyanoacetic acid was dried over phosphorus pentoxide at $40^{\circ} \mathrm{C}$ for 48 hours. Docetaxel and paclitaxel were purchased from Ningbo Chemical Factory (Ningbo, China). Soybean lecithin was supplied by Shanghai Taiwei Pharmaceutical Industry (Shanghai, China). Docetaxel injection $\left(\right.$ Taxotere $^{\circledR}$ ) was from Aventis Pharma SA (Antony Cedex, France), and coumarin-6 was from Sigma-Aldrich (St Louis, MO). All other chemicals and solvents were of reagent grade and the solvents were dehydrated by molecular sieving.

\section{Animals}

Male Wistar rats $(200 \pm 20 \mathrm{~g})$ and male Kunming strain mice (20-25 g) were from the Shenyang Pharmaceutical University Animal Institution. The rats were housed under standard conditions and were fed on a commercial diet and had access to water ad libitum. All animal experiments were carried out in accordance with the Guide for the Care and Use of Laboratory Animals of the National Research Council. The protocol was approved by the local animal ethics committee.

\section{Cell culture}

For cell culture, mouse connective tissue fibroblast cells (L929), human breast adenocarcinoma cells (MCF-7), and human lung adenocarcinoma cells (A-549) were obtained from Nanjing Keygen Biotech Co Ltd (Nanjing, China). The reagents employed in this study were as follows: RPMI 1640, F-12k medium (Hyclone, Logan, UT), fetal bovine serum (Gibco, Grand Island, NY), trypsin (Sigma-Aldrich) and dimethyl sulfoxide (Sigma-Aldrich). All other materials were used without further purification. All cells were maintained in a medium supplemented with penicillin 10\% (v/v) $100 \mathrm{U} / \mathrm{mL}$ and streptomycin $100 \mu \mathrm{g} / \mathrm{mL}$. Cells were incubated at $37^{\circ} \mathrm{C}$ in a humidified atmosphere containing $5 \% \mathrm{CO}_{2}$. 


\section{Synthesis of copolymers of FA-PEG-PCHL}

Preparation of cyanoacetate esters

The amino group of $\mathrm{NH}_{2}-\mathrm{PEG}-\mathrm{OH}$ was protected by making it into t-butyloxycarbonylamino- $\omega$-hydroxylpolyethyleneglycol (t-boc-NH $\mathrm{N}_{2}-\mathrm{PEG}-\mathrm{OH}$ ). ${ }^{18}$ As shown in Figure 1A, a mixture of $20 \mathrm{mmol}$ triethylamine, $18 \mathrm{mmol}$ di-t-butyl dicarbonate, and $20 \mathrm{mmol} \mathrm{NH}_{2}$-PEG2000-OH in
$300 \mathrm{~mL}$ dichloromethane was stirred for 72 hours. $\mathrm{HCl} 0.5$ $M$ was then added to the mixture. The organic layer was separated and washed with saturated $\mathrm{NaCl}$ solution. The organic phase was separated again and dried over $\mathrm{MgSO}_{4}$. The solvent was evaporated and the residue was allowed to cool under vacuum. t-boc-NH-PEG cyanoacetate was prepared by esterification of the cyanoacetic acid with bocNH-PEG-OH in dichloromethane at room temperature under
A

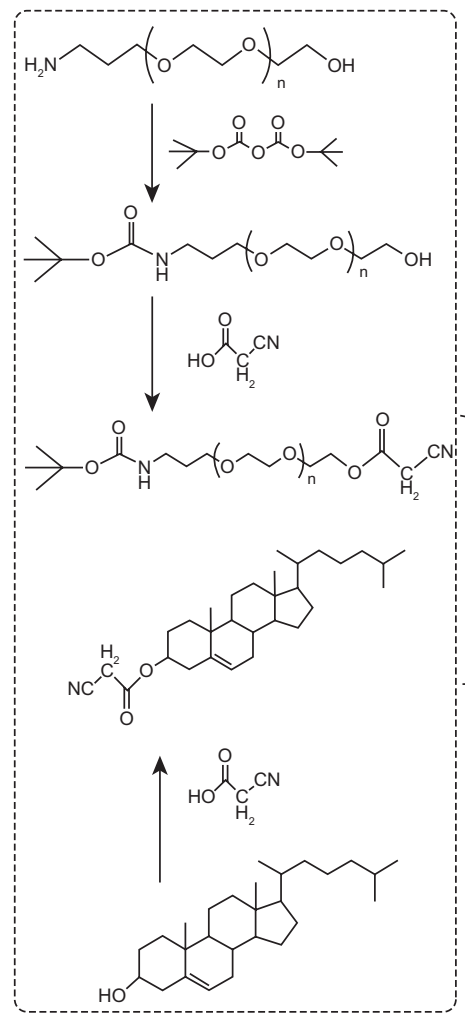

C

B
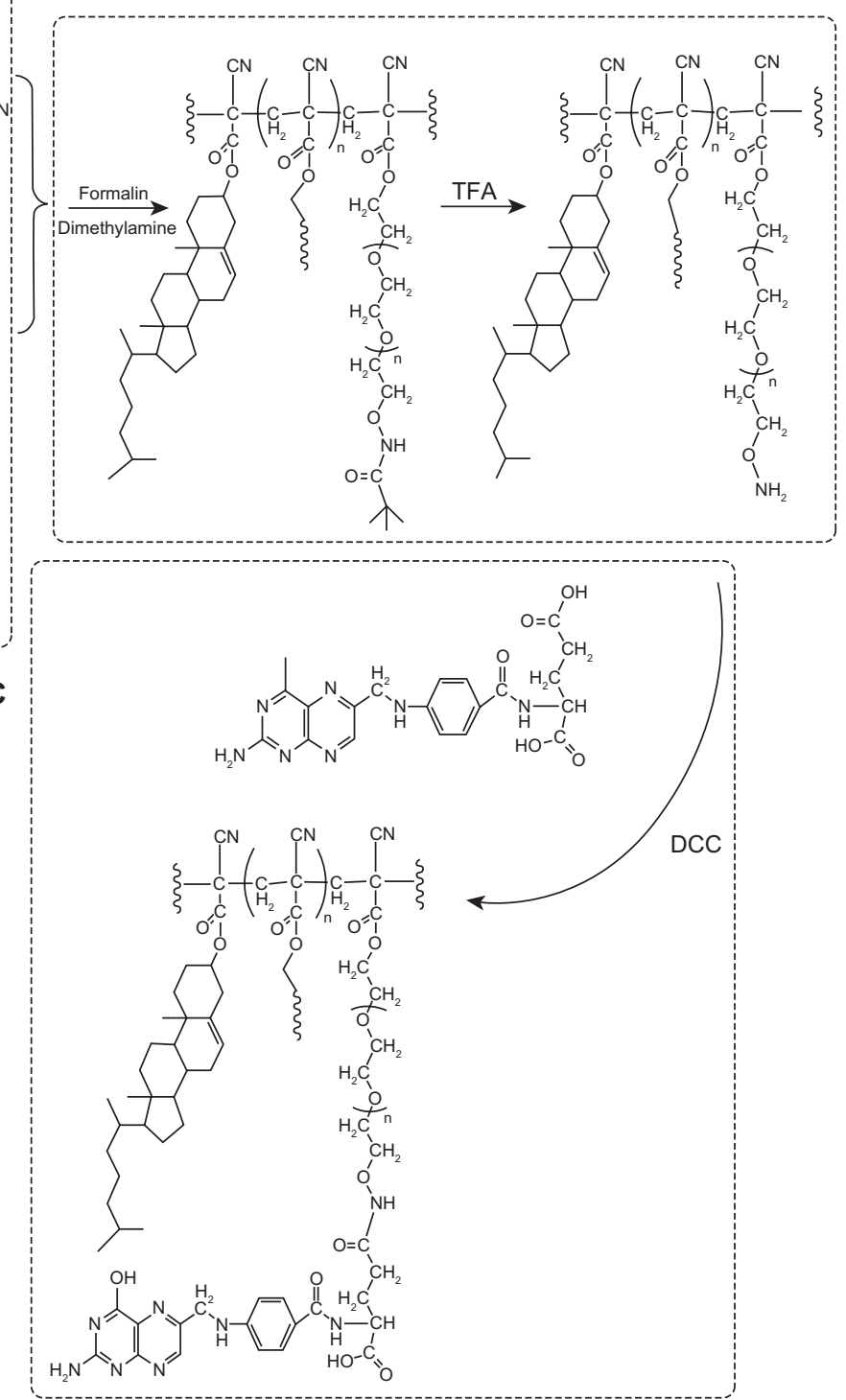

Figure I Synthesis of folate-poly (PEG-cyanoacrylate-co-cholesteryl cyanoacrylate) (FA-PEG-PCHL). 
nitrogen, in the presence of dicyclohexylcarbodiimide and DMAP as the catalyst. Cyanoacetic acid $10 \mathrm{mmol}$ and bocNH-PEG-OH $5 \mathrm{mmol}$ (molar ratio 2:1) were placed into a glass flask and dissolved in dichloromethane $40 \mathrm{~mL}$ and dicyclohexylcarbodiimide $11 \mathrm{mmol}$, and a catalytic amount of DMAP were added. After stirring for six hours, the solid was filtered off and washed three times with $\mathrm{CH}_{2} \mathrm{Cl}_{2} 15 \mathrm{~mL}$. The combined filtrates were concentrated under reduced pressure to obtain viscous oil which was solidified after 12 hours. The crude boc-NH-PEG cyanoacetate obtained was used directly in the polymerization step without further purification. The cyanoacetate ester of cholesterol was prepared according to the same procedure as aforementioned (Figure 1A).

\section{Condensation/polymerization}

The reaction scheme for condensation of $\mathrm{t}-\mathrm{boc}-\mathrm{NH}_{2}-\mathrm{PEG}$ cyanoacetate with cholesteryl cyanoacetate in the presence of formalin and dimethylamine, as previously described was shown in Figure 1B. Briefly, t-boc- $\mathrm{NH}_{2}-\mathrm{PEG}$ cyanoacetate $1 \mathrm{mmol}$ and cholesteryl cyanoacetate $5 \mathrm{mmol}$ were dissolved in ethanol/dichloromethane $20 \mathrm{~mL}(1: 1, \mathrm{v} / \mathrm{v})$ in a glass flask, and formalin $10 \mathrm{mmol}(37 \%, \mathrm{w} / \mathrm{v})$ and dimethylamine $10 \mathrm{mmol}\left(40 \%\right.$, w/v) were added. ${ }^{18}$ The reaction was carried out at room temperature under nitrogen. After stirring for 12 hours, the reaction mixture was poured into water and extracted with dichloromethane. The combined organic phases were dried over $\mathrm{MgSO}_{4}$. The solvent was evaporated, and the residue was placed several hours under vacuum to cool down.

The amino group of t-boc- $\mathrm{NH}_{2}$-PEG was deprotected by trifluoroacetic acid in dichloromethane (Figure 1B). ${ }^{19}$ Briefly, trifluoroacetic acid $1 \mathrm{~mL}$ was added to polymer $1 \mathrm{mmol}$ solution, and the reaction was carried out for one hour at room temperature under magnetic stirring. The reaction mixture was then neutralized with $10 \%$ aqueous sodium bicarbonate solution and extracted with dichloromethane. The organic layer was dried over $\mathrm{MgSO}_{4}$ and evaporated under reduced pressure to give a pale yellow waxy material.

\section{Conjugation of folic acid and $\mathrm{NH}_{2}$-PEG-PCHL}

Folate-conjugated co-copolymer was synthesized by coupling the $\mathrm{NH}_{2}$-PEG-PCHL to an activated folic acid as described in the previous studies with a minor modification. ${ }^{11,20,21}$ As shown in Figure $1 \mathrm{C}, \mathrm{NH}_{2}$-PEG-PCHL $1 \mathrm{mmol}$ dissolved in dimethyl sulfoxide $30 \mathrm{~mL}$ was mixed with folic acid $4 \mathrm{mmol}$ and dicyclohexylcarbodiimide $1.2 \mathrm{mmol}$, and two drops of triethylamine was then added as a catalyst. The reaction was performed at room temperature for 12 hours, and the reaction solution was then filtered. The filtrate was dialyzed in dimethyl sulfoxide for 72 hours to remove free folic acid and then dialyzed for another 72 hours to eliminate dimethyl sulfoxide. The mixture was freeze-dried in a dialysis bag to give the final product.

\section{Characterization of polymers} FTIR spectra, 'H-NMR spectra and MW of polymers

Fourier transform infrared (FTIR) spectra were obtained from a neat film cast from the dimethyl sulfoxide copolymer solution between $\mathrm{KBr}$ tablets on an FTIR spectrometer (IFS-55, Bruker Corporation, Switzerland). ${ }^{1} \mathrm{H}-\mathrm{NMR}$ spectra was recorded in deuterated pyridine for PEG-PCHL and in deuterated dimethyl sulfoxide for FA-PEG-PCHL by ${ }^{1} \mathrm{H}-\mathrm{NMR}$ spectroscopy (ARX-300, Bruker Corporation, Fällanden, Switzerland). Gel permeation chromatography of PEG-PCHL was performed in tetrahydrofuran (Fisher Scientific, Fair Lawn, NJ) of high-pressure liquid chromatography grade with a Waters Alliance 2690 separation module (Waters Corporation, Milford, MA) equipped with a set of two Waters Styragel columns having pore size diameters of $10^{3}$ and $100 \AA$, and a Waters 2410 refractive index detector (Waters Corporation). A series of narrow polystyrene (Polymer Laboratories, Amherst, MA) molecular weight standards $(30-500 \mathrm{kDa})$ were used to calibrate the gel permeation chromatography system.

\section{Cytotoxicity of polymers by CCK-8 assay}

The L929 cell line was selected to evaluate cytotoxicity as a direct contact test, as recommended by USP 26. The experiment was carried out according to the method described for the Cell-Counting Kit 8 (Fluka, St Louis, MO). ${ }^{22}$ The copolymers were added as free solutions. The relative cell viability compared with control cells containing cell culture medium without polymer was calculated as $[\mathrm{A}]_{\text {test }} /[\mathrm{A}]_{\text {control }}$.

\section{Liposome preparation}

Liposomes were prepared using an organic solvent injection method. ${ }^{23}$ Briefly, in all formulations containing polymers of different molecular weight, a mixture of FA-PEGPCHL $0.005 \mathrm{mmol}$, docetaxel $0.012 \mathrm{mmol}$, and soybean lecithin $0.25 \mathrm{mmol}$ was dissolved in tetrahydrofuran $5 \mathrm{~mL}$. The solution was injected into purified water at $25^{\circ} \mathrm{C}$ and the suspension obtained was stirred for 180 minutes to facilitate the removal of tetrahydrofuran. To obtain a uniform particle size distribution, the suspension was sonicated at a frequency of $20-25 \mathrm{kHz}$ and power of $500 \mathrm{~W}$ for 2.5 minutes by a probe-type sonicator (JY92-II, Scientz, Ningbo, China) 
and then sterilized by filtering through a $0.22 \mu \mathrm{m}$ cellulose acetate filter. Appropriate amounts of cryoprotectants $(5 \%, \mathrm{w} / \mathrm{v})$ were dissolved in the liposome dispersion. The samples were frozen at $-85^{\circ} \mathrm{C}$ for eight hours before being lyophilized using a freeze drier (Eyela FDU-1100, Prkakikai, Tokyo, Japan). The drying time was 36 hours. The resulting solid matrix was collected for later experiments after rehydration with deionized water.

\section{Characterization of liposomes}

\section{Transmission electron microscopy}

FA-PDCT-L were viewed before and after lyophilization under an electron microscope (JEM-1200 EX, JEOL, Tokyo, Japan) by conventional negative staining methods using phosphotungstic acid buffer $0.3 \%(\mathrm{pH} 6.0)$ as a staining agent. ${ }^{23}$

\section{Particle size distribution, zeta potentials,} and fixed aqueous layer thickness

Particle size distribution and zeta potentials for FA-PDCT-L were determined by dynamic light scattering and electrophoretic light scattering, respectively, both using ELS 800 apparatus (Otsuka Electronics, Osaka, Japan) at $25^{\circ} \mathrm{C}$ after dilution of the dispersion to an appropriate volume with Millipore-filtered water. According to the Gouy-Chapmann theory, the zeta potentials of samples diluted with $\mathrm{NaCl}$ solutions at a series of concentrations $(0 \mathrm{M}, 0.01 \mathrm{M}, 0.05 \mathrm{M}$, and $0.1 \mathrm{M}$ ) measured and plotted against the slope L gives the position of the slipping plane or fixed aqueous layer thickness FALT) in nm units. FALT was calculated by:

$$
\ln \psi(\mathrm{L})=\ln \mathrm{A}-\kappa \mathrm{L}
$$

where $\psi(\mathrm{L})$ is the electrostatic potential at the position of the slipping plane $\mathrm{L}(\mathrm{nm}), \mathrm{A}$ is the constant, and $\kappa$ is the Debye-Huckel parameter which equals $\mathrm{C}^{-2} / 0.3$ for univalent salts, where $\mathrm{C}$ is the molality of electrolytes. ${ }^{24}$

\section{Determination of entrapment efficiency}

The liposome entrapment efficiency was determined using an ultrafiltration technique for separating the nonentrapped drug from liposomes. ${ }^{25}$ Briefly, $5 \mathrm{~mL}$ of drug-loaded liposomes were placed in a stirred cell (Millipore 8010, Millipore Corporation, Bedford, MA) fitted with a filter membrane (molecular weight cutoff 50,000) under nitrogen. The ultrafiltrate was collected, and the drug content in the ultrafiltrate $\left(\mathrm{C}_{\text {free }}\right)$ was determined by high-pressure liquid chromatography using an LC-ATvp pump and SPD-10 Avp ultraviolet light detector (Shimadzu, Kyoto, Japan) and a
Diamonsil $\mathrm{C}_{18}$ analytical column $250 \mathrm{~mm} \times 4.6 \mathrm{~mm}, 5 \mu \mathrm{m}$ (Dikma, Tianjin, China). ${ }^{26}$ The injection volume was $20 \mu \mathrm{L}$ and docetaxel was detected at $228 \mathrm{~nm}$. The mobile phase consisted of acetonitrile and water $(53: 47, \mathrm{v} / \mathrm{v})$ delivered at a flow rate of $1.0 \mathrm{~mL} /$ minute. A liposomal suspension $1 \mathrm{~mL}$ was then diluted with absolute ethanol to determine the total docetaxel $\left(\mathrm{C}_{\text {total }}\right)$ by high-pressure liquid chromatography. The entrapment efficiency (EE\%) was calculated as:

$$
\mathrm{EE} \%=\frac{c_{\text {total }}-c_{\text {free }}}{c_{\text {total }}} \times 100
$$

\section{In vitro drug release}

The drug release profile for the docetaxel-loaded liposomes was studied using a dialysis method in vitro. Briefly, an aliquot of FA-PDCT-L were diluted 50-fold with phosphate buffer $(0.1 \mathrm{M}, \mathrm{pH} 7.4)$ containing Tween $80(0.3 \%$, w/v), thereby improving the solubility of docetaxel in phosphatebuffered saline, and incubated in buffer at $37^{\circ} \mathrm{C}$ under magnetic stirring in a dialysis bag (molecular weight cutoff $7000 \mathrm{Da})$. Aliquots of $1 \mathrm{~mL}$ were withdrawn from the release medium and replaced by an equal volume at each sampling time. The amount of docetaxel was determined by highpressure liquid chromatography. All operations were carried out in triplicate.

\section{Cytotoxicity of liposomes}

A CCK-8 assay was performed to compare the cytotoxic effects of docetaxel solution, FA-PDCT-L, and empty FAPEG-PCHL-modified liposomes (FA-P-L) against two cancer cell lines in vitro using a previously established method. ${ }^{27-29}$ Before the experiment, MCF-7 breast cancer cells and A-549 lung cancer cells were precultured until confluence was reached. After incubating the cells in docetaxel solution, FA-PDCT-L, and FA-P-L for 24, 48, and 72 hours, with docetaxel concentrations ranging from $0.5 \mathrm{nM}$ to $40 \mathrm{nM}$, the CCK-8 assay was performed and the percentage cell viability was determined. Error bars were obtained from triplicate samples.

\section{In vitro cellular uptake of liposomes}

Confocal laser scanning microscopy was used to visualize the interaction of the colloidal particles with the cancer cells. For fluorescence imaging of cellular uptake, MCF-7 cells at a density of $1 \times 10^{6}$ cells $/ \mathrm{mL}$ were cultivated for 24 hours on coverslips in six-well culture plates ( $1 \mathrm{~mL} /$ well). Coumarin-6 solution was prepared following the same prescription and preparation process as for Taxotere. 
Suspensions of coumarin-6-loaded liposomes (COU-L) and coumarin-6-loaded FA-PEG4000-PCHL-modified liposomes (FA-PCOU4000-L) were then added $(200 \mu \mathrm{L} /$ well) to the cell culture medium at a concentration of $100 \mu \mathrm{g} / \mathrm{mL}$. Cells were washed three times after incubation for two hours and then fixed using 4\% (v/v) paraformaldehyde aqueous solution. After 10 minutes of fixing at room temperature, followed by rinsing with phosphate-buffered saline, propidium iodide $10 \mu \mathrm{g} / \mathrm{mL}$ in phosphate-buffered saline was added to stain the nuclei for 30 minutes. The stained cells were then washed with phosphate-buffered saline and observed using a confocal laser scanning microscopy system (TCS SP2/AOBS, Leica, Germany).

\section{Acridine orange/ethidium bromide staining}

Morphological demonstration of apoptosis was done using acridine orange/ethidium bromide staining. MCF-7 cells were cultured and divided into control and test groups. Normal cells were treated with serum-free medium for 24 hours. Test groups were treated with docetaxel solution, docetaxel-loaded liposomes, and FA-PDCT-L, respectively, for 24 hours at a docetaxel concentration of $20 \mu \mathrm{g} / \mathrm{mL}$. After removal of the incubation medium, MCF-7 cells were harvested with trypsin $0.25 \%$ solution and treated with dye mixture (a normal/apoptotic/necrotic cell detection kit, Nanjing KeyGen Biotech Co Ltd, China). Double-staining using these two agents provided the percentage of live, apoptotic, and necrotic cells. The cells were observed immediately using an Olympus B × 61 fluorescence microscope (Tokyo, Japan) and the appropriate fluorescein filter. Acridine orange exhibits green fluorescence and ethidium bromide exhibits red fluorescence when bound to DNA. In this way, it is possible to distinguish between viable (green fluorescence with intact nucleus), early apoptotic (green fluorescence with chromatin condensation), late apoptotic (orange fluorescence with chromatin condensation), and necrotic cells (orange fluorescence with intact nucleus).

\section{Annexin V/propidium iodide double staining}

MCF-7 cells were divided and treated as aforementioned, then detached by trypsin and washed twice. Apoptotic cells were identified by binding of fluorescein-labeled annexin $\mathrm{V}$ to exposed phosphatidylserine on the cell surface and necrosis by nuclear staining with propidium iodide. Cell clusters were identified as described in the annexin V-FITC staining kit (Nanjing KeyGen Biotech Co Ltd, China) according to the manufacturer's recommendations with flow cytometric analysis (FACSCalibur, BD Biosciences, San Jose, CA), and a dot plot of FL1 (annexin V) and FL2 (propidium iodide) was constructed to show the gated events. Quadrant markers were applied to identify the four cell populations (annexin V-/ propidium iodide+, annexin $\mathrm{V}+$ /propidium iodide + , annexin $\mathrm{V}-$ /propidium iodide-, annexin $\mathrm{V}+$ /propidium iodide-). The results were expressed as a percentage of the gated events. ${ }^{9}$

\section{Pharmacokinetics}

Twelve male Wistar rats were fasted overnight and randomly divided into two groups of six rats each for an in vivo pharmacokinetics study. A docetaxel solution as a reference and FA-PDCT-L were injected intravenously at a dose of $10 \mathrm{mg} / \mathrm{kg}$. Blood samples were collected from the orbital plexus at predetermined time points into heparinized tubes and then centrifuged at $5000 \mathrm{rpm}$ for five minutes to separate the plasma.

To analyze the plasma samples, paclitaxel $(20 \mu \mathrm{L}$ of a methanol $10 \mu \mathrm{g} / \mathrm{mL}$ solution) was added as the internal standard to $200 \mu \mathrm{L}$ of plasma and the mixture was extracted with ether before being centrifuged. Docetaxel in the supernatant was dried under nitrogen and redissolved in methanol for liquid chromatography-mass spectrometry measurement. The assay was performed on a liquid chromatography-mass spectrometry system (2010A, Shimadzu). Liquid chromatographic separation was achieved on a Kromasil $\mathrm{C}_{18}$ column $(150 \mathrm{~mm} \times 4.6 \mathrm{~mm}, 5 \mu \mathrm{m})$ and preceded by a $\mathrm{C}_{18}$ guard column (4.0 $\mathrm{mm} \times 2.0 \mathrm{~mm}$, Phenomenex, Torrance, CA). The column and autosampler tray temperatures were kept constant at $25^{\circ} \mathrm{C}$ and $4^{\circ} \mathrm{C}$, respectively. The mobile phase was methanol and water $(75: 25, \mathrm{v} / \mathrm{v})$. The flow rate was set at $0.8 \mathrm{~mL} / \mathrm{min}$, with $25 \%$ of the eluent splitted into the inlet of the mass spectrometer. The injection volume was $10 \mu \mathrm{L}$.

The analytes were ionized by an ESI source in positive ion mode under the following source conditions: nebulizing gas $1.5 \mathrm{~L} / \mathrm{min}$; drying gas $2.0 \mathrm{~L} / \mathrm{min}$; curved desolvation line temperature $250^{\circ} \mathrm{C}$; heat block temperature $200^{\circ} \mathrm{C}$; detector voltage $1.70 \mathrm{kV}$; and other parameters fixed as for the tuning file. Analysis was carried out by selected ion monitoring at $[\mathrm{M}+\mathrm{Na}]^{+} \mathrm{m} / \mathrm{z} 830.50$ for docetaxel and at $[\mathrm{M}+\mathrm{Na}]^{+} \mathrm{m} / \mathrm{z}$ 876.50 for paclitaxel. The internal standard ratio was calculated for each standard by dividing the analyte peak area by the peak area of the internal standard. Standard curves of docetaxel and paclitaxel were constructed by plotting the internal standard ratio versus the concentration of analyte in each sample. Standard curves were fit by linear regression with weighting by $1 / \mathrm{y}^{2}$, followed by back calculation of concentrations. 


\section{Tissue distribution of liposomes in sarcoma- 180 solid tumor-bearing mice} Male Kunming mice, body weight 20-25 g, were used for biodistribution studies after sarcoma-180 cells were implanted intradermally into the armpit for one week. Twenty-seven tumor-bearing mice were fasted overnight and randomly divided into three groups of nine mice each. Docetaxel solution, docetaxel-loaded liposomes for reference, and reconstituted freeze-dried FA-PEG4000-PCHLmodified docetaxel liposomes (FA-PDCT4000-L) were injected intravenously at a dose of $20 \mathrm{mg} / \mathrm{kg}$. Another three animals were sacrificed without treatment, and their tissues were used as blank controls and for preparation of spiked control samples.

The animals were decapitated in groups of three at seven, 120, and 240 minutes, and the heart, liver, spleen, lungs, kidneys, brain, and tumor tissue were removed, washed of residual blood, air-dried, and weighed. Tissue samples were homogenized with saline $0.2 \mathrm{mg} / \mathrm{mL}$, and methanol solution $20 \mu \mathrm{L}$ containing paclitaxel $10 \mu \mathrm{g} / \mathrm{mL}$ was then added as the internal standard. Tissue samples were extracted with ether and then centrifuged. The supernatants were dried under nitrogen and redissolved in methanol for liquid chromatography-mass spectrometry measurement as described earlier.

\section{Statistical analysis}

Statistical analysis of the cytotoxicity of FA-PEG2000PCHL, FA-PEG4000-PCHL, and FA-PEG10000-PCHL, and the effects of the three polymers on particle size, zeta potentials, FALT, entrapment efficiency, and mean 24-hour cumulative release (\%) of the various formulations were performed using the Kruskal-Wallis test. In all cases, post hoc comparisons of the means of individual groups were performed using the least significant difference test.

Plasma drug concentration-time data for docetaxel in individual rats were analyzed by noncompartmental estimations using 3p87 software (Chinese Society of Mathematical Pharmacology, Beijing, China). Plasma and tissue concentrations of docetaxel obtained from the rats were pooled to provide mean concentrations. Statistical analysis of the pharmacokinetic parameters (peak concentration $\left[\mathrm{C}_{\max }\right]$, clearance, mean residence time from time 0 extrapolated to infinity [MRT] and area under the plasma-concentration time curve from time 0 extrapolated to infinity [AUC]) for the docetaxel solution, docetaxel-loaded liposomes, and FA-PDCT4000-L were carried out using the one-way analysis of variance $t$-test. Differences in tissue drug concentrations at different time points were estimated using the Kruskal-Wallis test, and post hoc comparisons of the means of individual groups were performed using the least significant difference test. A significance level of $P<0.05$ denoted significance in all cases. Statistical analysis was performed using SPSS version 17.0 (SPSS Inc, Chicago, IL). Each experiment was conducted three times to ascertain reproducibility.

\section{Results and discussion Characterization of polymers FTIR spectra}

The FTIR spectrum of $\mathrm{NH}_{2}$-PEG-PCHL (Figure 2A) showed absorption bands related to the $\mathrm{CN}$ stretching vibration at $2177.6 \mathrm{~cm}^{-1}$ and the ester carbonyl at $1741.6 \mathrm{~cm}^{-1}$. The $\mathrm{C}-\mathrm{O}$ stretching of $\mathrm{PEG}$ appeared at $1112.0 \mathrm{~cm}^{-1}$. The FTIR spectrum of FA-PEG-PCHL (Figure 2B) showed absorption bands related to $\mathrm{CN}$ stretching vibration at $2244.0 \mathrm{~cm}^{-1}$ and the ester carbonyl at $1741.8 \mathrm{~cm}^{-1}$. The $\mathrm{C}-\mathrm{O}$ stretching of PEG appeared at $1108.9 \mathrm{~cm}^{-1}$. The $\mathrm{C}=\mathrm{C}$ and $=\mathrm{C}-\mathrm{H}$ stretching vibration of aromatic ring of folate showed at 1536.9 and $842.5 \mathrm{~cm}^{-1}$, respectively.

\section{'H-NMR spectra}

The ${ }^{1} \mathrm{H}-\mathrm{NMR}$ spectra were consistent with the structure of the expected polymers. Figure 3 shows the spectrum of PEG-PCHL. The peaks at 3.70-4.20 ppm were attributed to the methylene in the R-position of the ester groups. The signal at 2.20-2.80 ppm and the resonance at $3.62 \mathrm{ppm}$ were assigned to the methylene protons of poly(cyanoacrylate) and the PEG backbone, respectively. Signals at $0.84-2.20 \mathrm{ppm}$ were assigned to the methylene and methyl protons of the cholesteryl skeleton. The peak at $0.66 \mathrm{ppm}$ was attributed to the methyl protons of the cholesteryl side chain. Figure 4 shows the spectrum of FA-PEG-PCHL. The peaks at 3.70-4.20 ppm were attributed to the methylene in the R-position of the ester groups. The resonance at $3.51 \mathrm{ppm}$ was assigned to the methylene protons of the PEG backbone. The signal at $2.00-2.40 \mathrm{ppm}$ and the resonance at $4.50 \mathrm{ppm}$ were attributed to the methylene in the R-position for the amide groups of folate, respectively. The signals at $6.61 \mathrm{ppm}, 7.41 \mathrm{ppm}$, and the resonance at $8.66 \mathrm{ppm}$ were attributed to the protons of the aromatic ring of folate, separately. Signals at $0.80-2.00$ ppm were assigned to the methylene and methyl protons of the cholesteryl skeleton. The peak at $0.65 \mathrm{ppm}$ was attributed to the methyl protons of the cholesteryl side chain.

\section{Molecular weights}

The molecular weights of the obtained polymers, as well as the polydispersity indices, were calculated by gel permeation 


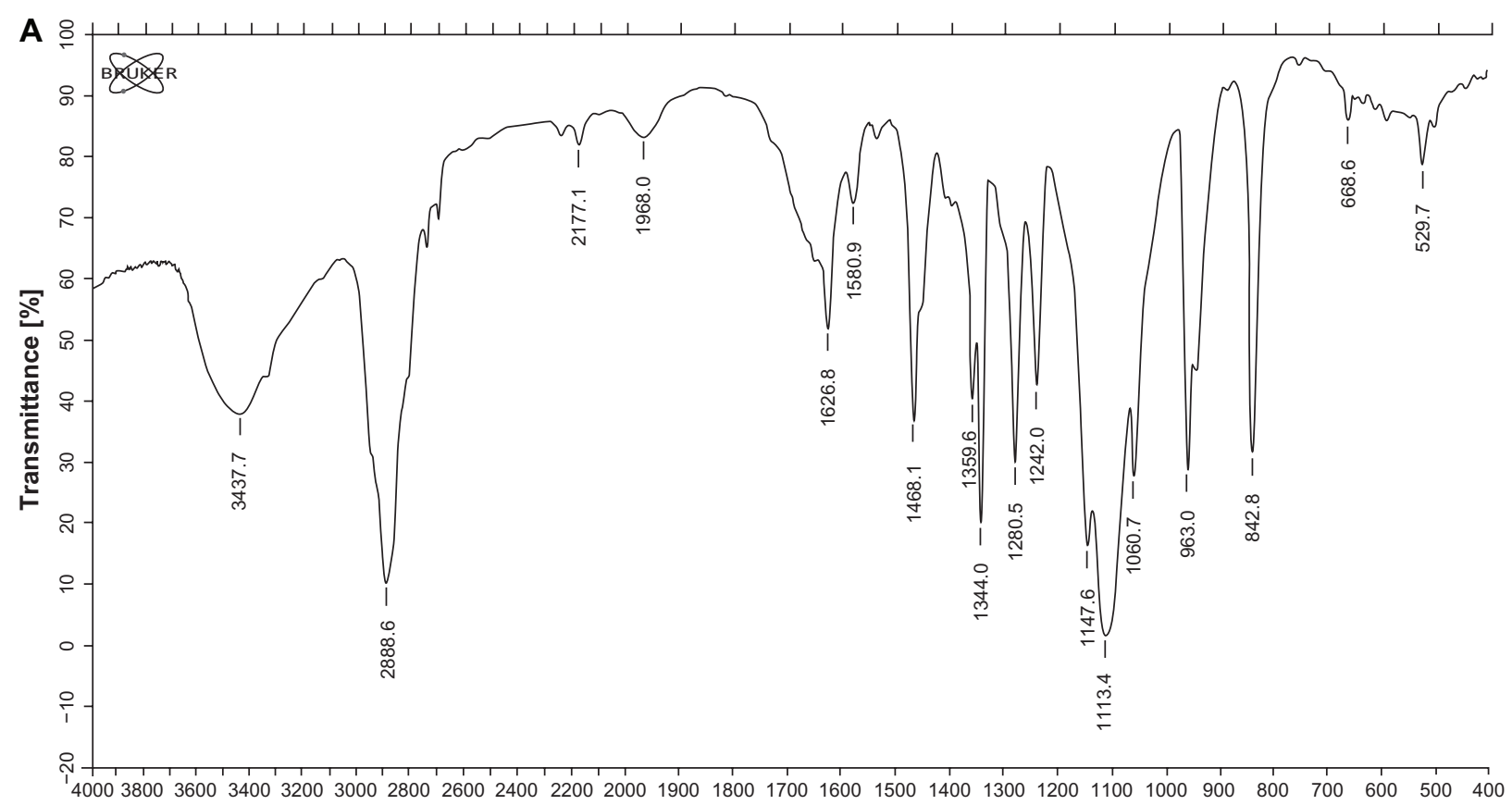

Wavenumber $\left(\mathrm{cm}^{-1}\right)$

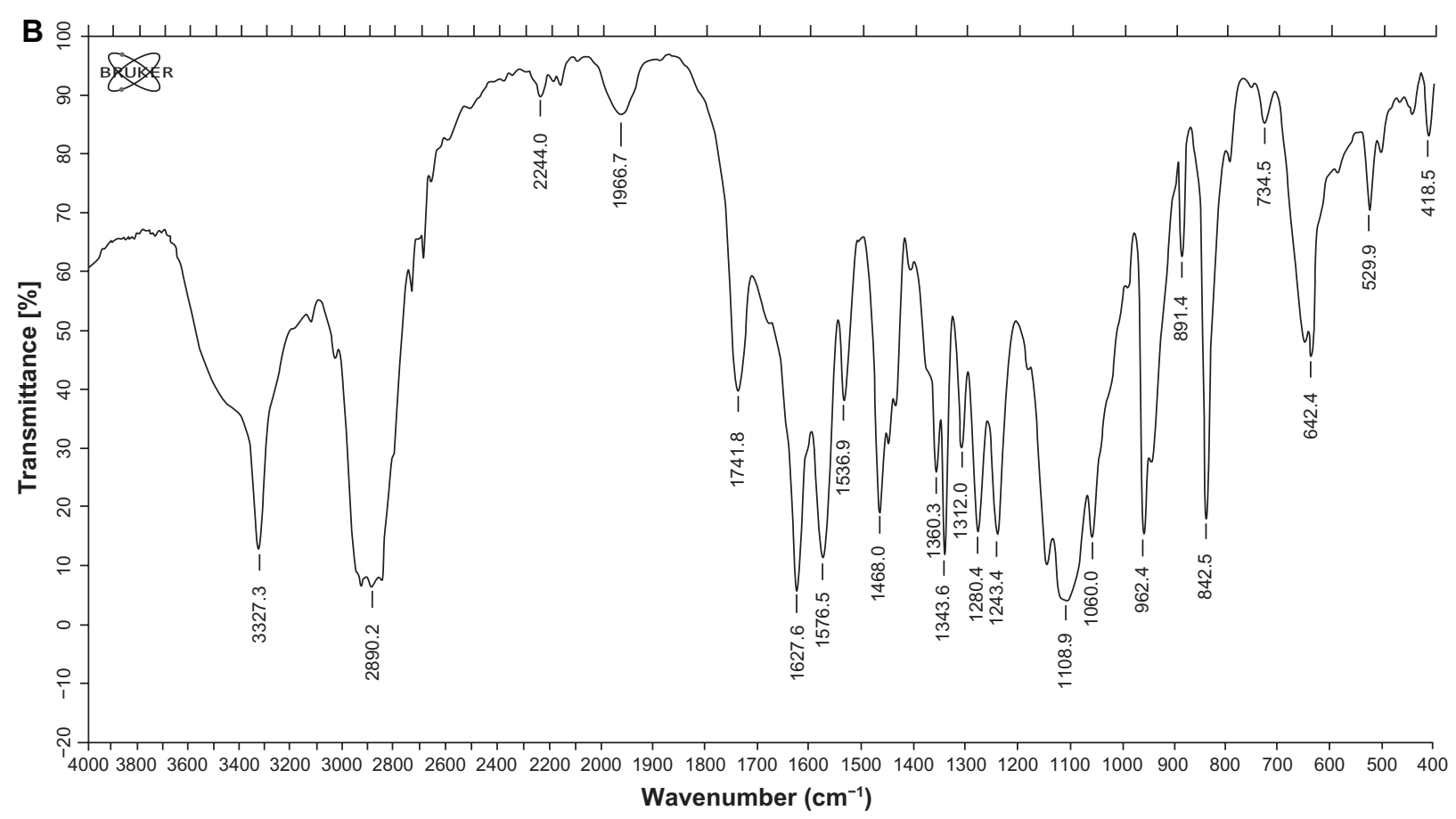

Figure 2 FTIR spectra of $\mathrm{NH}_{2}$-PEG-PCHL (A) and FA-PEG-PCHL (B).

chromatography. Table 1 reports the data for polymers with different chain lengths of PEG. A low molecular weight and low polydispersity index were achieved. The unimodal mass distribution excluded the presence of poly-(PEG acrylate) or poly-(cholesteryl acrylate). Because the condensation of alkyl cyanoacetates with formaldehyde is a method described for the synthesis of alkyl cyanoacrylate monomers, the formation of a poly-(alkyl cyanoacrylate) with a low molecular weight was expected. ${ }^{18}$ Furthermore, the interest in using poly-(alkylcyanoacrylate) in controlled drug delivery is due to its rapid degradability by erosion after hydrolysis of the lateral ester chain and the formation of water-soluble poly-(cyanoacrylic acid), which is eliminated by renal excretion..$^{30}$ Thus, a low molecular weight is an important issue for the degradability 


\begin{tabular}{cc}
\hline Protons & $\begin{array}{c}\text { Chemical shift } \\
(\mathrm{ppm})\end{array}$ \\
\hline a & $3.70-4.20$ \\
b & 3.62 \\
c & $0.84-2.20$ \\
d & $2.20-2.80$ \\
e & 0.66 \\
\hline
\end{tabular}
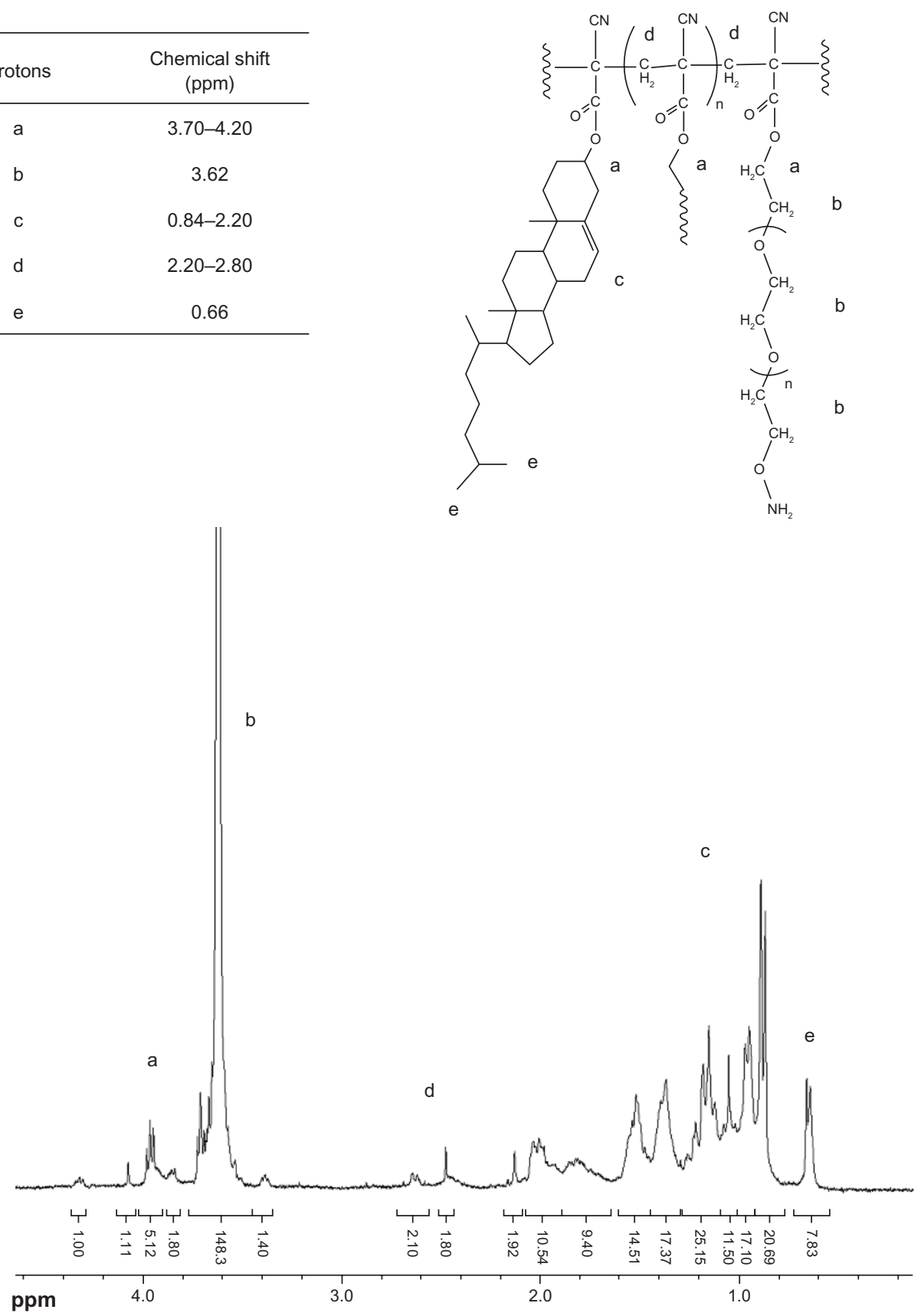

Figure 3 'H-NMR spectrum of PEG-PCHL.

properties of the obtained material. Finally, the molecular weight of the "hydrophobic" alkyl cyanoacrylate part of the copolymer was of the same order as that observed in nanoparticles prepared by emulsion/butyl cyanoacrylate, wellknown to degrade rapidly in vivo. ${ }^{31}$

\section{Cytotoxicity by CCK-8 assay}

The relative cell viability compared with control cells containing cell culture medium without polymer was calculated by $[\mathrm{A}]_{\text {test }} /[\mathrm{A}]_{\text {control }}$. Based on the viability of L929 cells incubated together with various polymers, FA-PEG-PCHL showed no cytotoxicity with experimental concentrations up to $1500 \mu \mathrm{g} / \mathrm{mL}$ in cell culture (Figure 5). No significant difference was found between the groups $(P>0.05)$.

\section{Characterization of liposomes Investigation of cryoprotectants}

Liposomal lyophilization is one of the most promising procedures for keeping liposomes stable during long-term storage. ${ }^{32}$ Therefore, different cryoprotectants, ie, lactose, 


\begin{tabular}{cc}
\hline Protons & $\begin{array}{c}\text { Chemical shift } \\
(\mathrm{ppm})\end{array}$ \\
\hline a & $3.70-4.20$ \\
b & 3.51 \\
c & $2.00-2.40$ \\
d & $0.80-2.00$ \\
e & $6.61,7.41$ \\
f & 8.66 \\
g & 0.65 \\
h & 4.50 \\
\hline
\end{tabular}

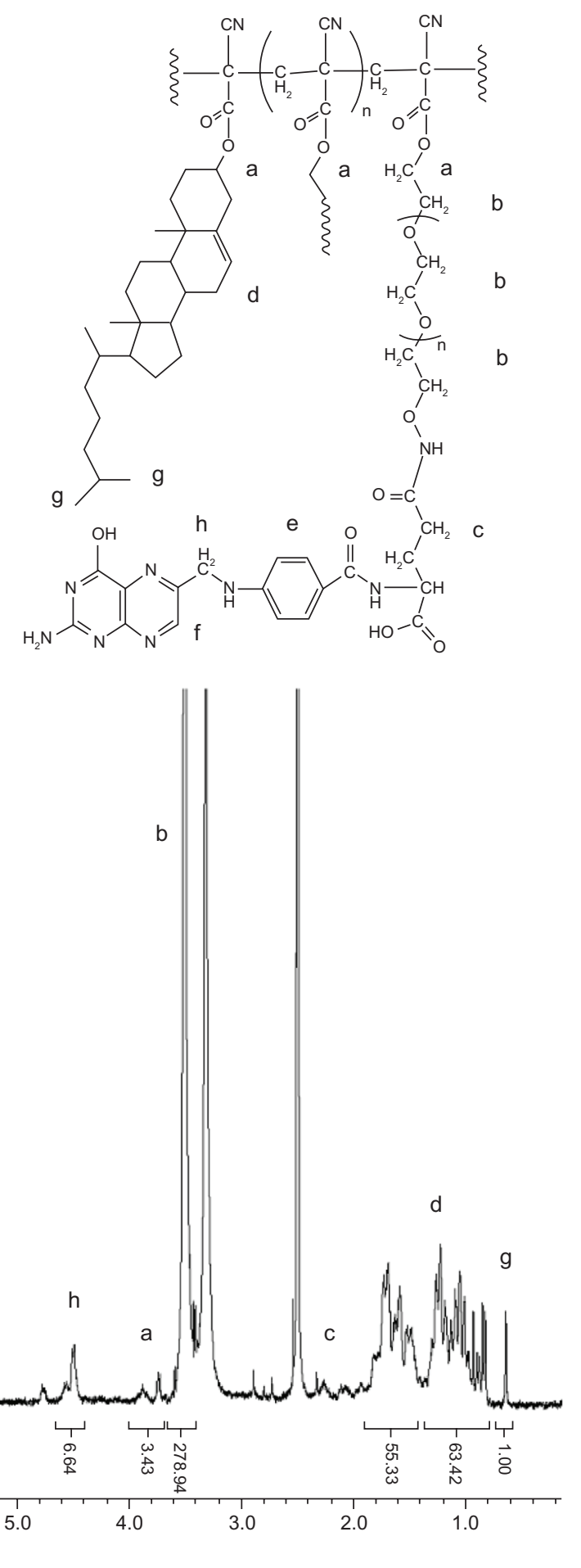

Figure 4 'H-NMR spectrum of FA-PEG-PCHL.

dextran, sucrose, trehalose, and mannitol ( $\%, w / v)$, were evaluated as candidates after preliminary experiments according to the appearance, morphology, and stability of the lyophilized liposomes after reconstitution.

In terms of the protective effect of lyoprotectants (lactose, sucrose, trehalose, and dextran), the size and encapsulation efficiency of FA-PDCT-L before and after lyophilization were similar (data not shown). In particular, the dried product obtained with trehalose was satisfactory in appearance and was easy to reconstitute, with an unchanged and uniform size distribution. As far as mannitol was concerned, the lyophilized product had a smooth and bright appearance, 
Table I MWs and polydispersity index of polymers

\begin{tabular}{lcl}
\hline & MW & Polydispersity index \\
\hline PEG2000-PCHL & $4374 \pm 91$ & 1.3 \\
PEG4000-PCHL & $6388 \pm 115$ & 1.4 \\
PEGI0000-PCHL & $12394 \pm 415$ & 1.7 \\
\hline
\end{tabular}

Note: Values are mean $\pm S D(n=3)$.

but was difficult to rehydrate, together with a significant increase in particle size. Therefore, we chose trehalose as the lyoprotectant $(5 \%, \mathrm{w} / \mathrm{v})$.

\section{Morphology analysis}

The morphological images of FA-PDCT-L before and after lyophilization are shown in Figure 6. In all cases, spherical or ellipsoid-shaped particles were found.

\section{PSD, zeta potentials, FALT, and entrapment efficiency} A unimodal particle size distribution was observed, and FAPDCT-L with polymers of different molecular weight had a similar particle size distribution, ranging from $111 \mathrm{~nm}$ to $127 \mathrm{~nm}$, as shown in Table 2. Meanwhile, the negativity of the zeta potential for the liposomes decreased dramatically with increasing PEG chain length $(P<0.05)$. Increasing $\mathrm{NaCl}$ concentration also led to reduction of the negative surface charge of the liposomes, indicating that the FALT of the liposomes increased dramatically with length of the PEG chain $(P<0.05)$. The data suggested that the surface structure of FA-PDCT-L fitted a "mushroom" structure, with FALT no more than $10 \mathrm{~nm} .{ }^{33}$ "Mushroom" structure theory postulates that PEG, folding on the surface of the liposomes due to its compressibility, is favorable for liposomes to prevent aggregation and improve its ability to evade uptake by macrophages. The entrapment efficiency of liposomes with or without modification was not significantly different, indicating that the loading of polymers did not change the encapsulation ability of the liposomes.

\section{In vitro release}

There was no obvious burst release of drug for up to 24 hours, and a prolonged release phenomenon was showed in all groups (Figure 7). The release rate was faster with higher molecular weights of the polymer, showing a molecular-dependent release profile. The cumulative amount of docetaxel released within 24 hours was $40.8 \%$ for docetaxel-loaded liposomes, while a significant decreased amount of docetaxel in FAPDCT-L was released over 24 hours, ie, 19.5\%, 27.2\%, and $31.1 \%$ for FA-PDCT2000-L, FA-PDCT4000-L, and FAPDCT10000-L, respectively $(P<0.05)$. Polymer-modified liposomes released drug significantly more slowly than nonmodified liposomes because of the poly (cholesteryl

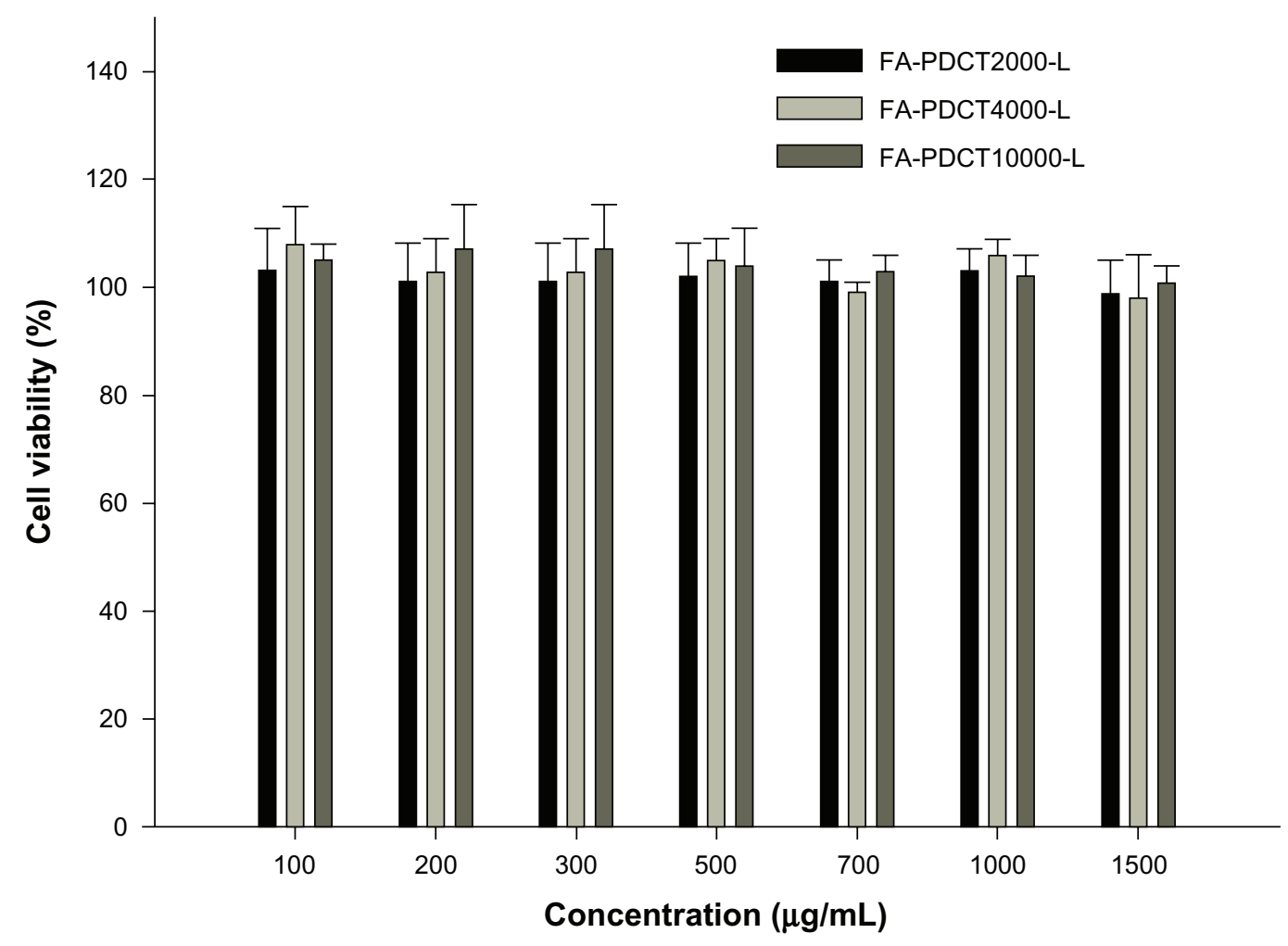

Figure 5 Cytotoxicity of FA-PDCT2000-L, FA-PDCT4000-L, and FA-PDCTI0000-L in L929 $(\mathrm{n}=3)$. The polymers were added as free solutions. 

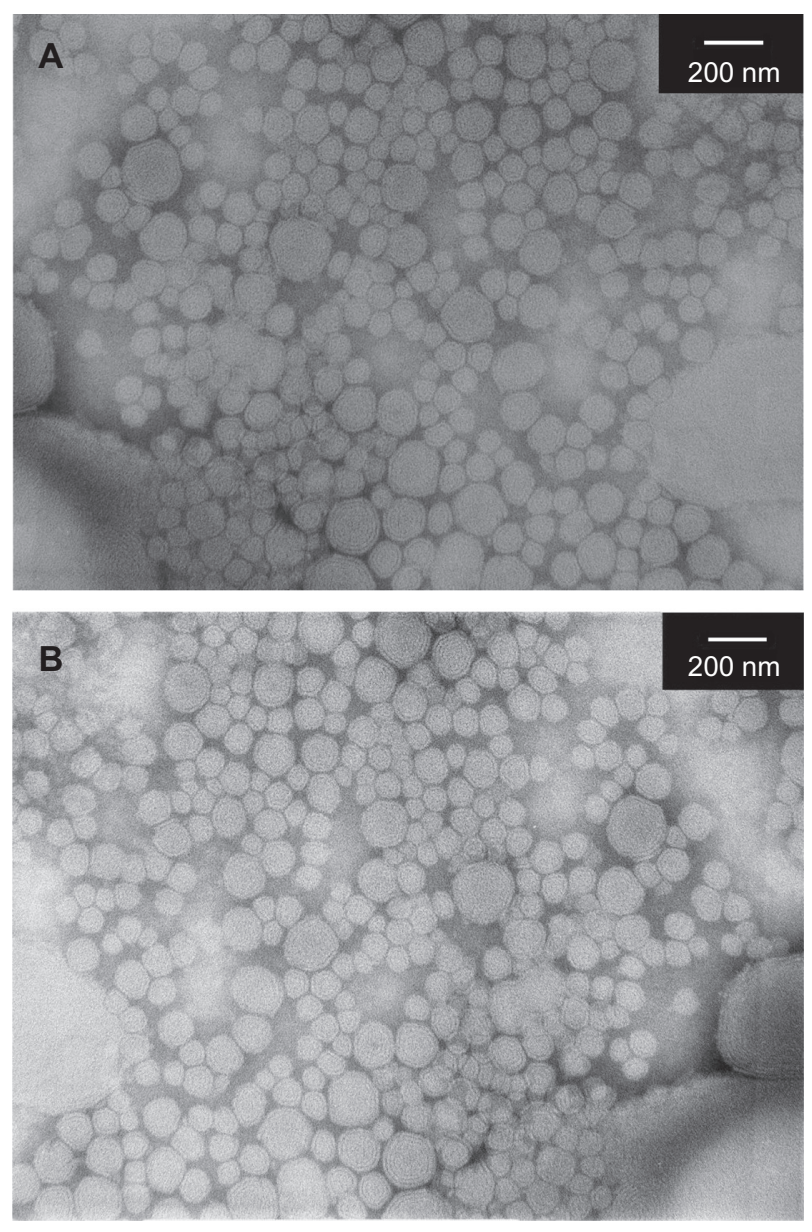

Figure 6 Transmission electron microscopy images of FA-PDCT-L before (A) and after (B) lyophilization.

cyanoacrylate) moieties in the polymer. Cholesterol is known to enhance the rigidity of the lethicin bilayer. ${ }^{34}$ As a result, incorporation of the polymer possibly altered the flexibility of the liposomal bilayer, and reduced the rate of drug release. We also observed that the mass of the hydrophilic group of the polymer significantly influenced the rate of drug release. The higher the chain length of PEG, the faster the rate of drug release, and this may be attributable to the loose structure of FA-PDCT10000-L, leading to accelerating drug release.

\section{Cytotoxicity of liposomes}

The in vitro cytotoxic activity of docetaxel solution, docetaxelloaded liposomes, and FA-PDCT-L is shown in Table 3. The $\mathrm{IC}_{50}$ of FA-PDCT2000-L, FA-PDCT4000-L, and FAPDCT10000-L was significantly lower than that of docetaxel solution and docetaxel-loaded liposomes in both cancer cell lines for all incubation time periods. FA-PDCT4000-L showed significant advantages in inhibiting cancer cell proliferation when compared with the docetaxel solution and docetaxelloaded liposomes. In comparison with docetaxel solution, the $\mathrm{IC}_{50}$ for FA-PDCT4000-L decreased to $83.6 \%, 71.1 \%$, and $58.4 \%$ in the MCF- 7 line, and to $76.3 \%, 65.3 \%$, and $66.3 \%$ in the A-549 line after 24, 48, and 72 hours of treatment, respectively, while in comparison with docetaxel-loaded liposomes, the $\mathrm{IC}_{50}$ for FA-PDCT4000-L decreased to $82.6 \%, 75.9 \%$, and $65.5 \%$ in the MCF-7 line and to $74.6 \%, 75.9 \%$, and $67.8 \%$ in the A-549 line after 24, 48, and 72 hours of treatment, respectively, showing a significant reduction in $\mathrm{IC}_{50}$ values. Compared with FA-PDCT2000-L and FA-PDCT4000-L, the $\mathrm{IC}_{50}$ of FA-PDCT10000-L was significantly higher in both cell lines. FA-P-L demonstrated no significant cytotoxic effect in either the MCF-7 line or in the A-549 line, even at concentrations as high as $1000 \mu \mathrm{g} / \mathrm{mL}$ (data not shown). $\mathrm{IC}_{50}$ values could not be determined accurately for FA-P-L.

In vitro cytotoxicity studies showed that FA-PDCT-L was significantly more cytotoxic in MCF-7 and A-529 lines compared with the docetaxel solution and docetaxel-loaded liposomes (Table 3). Higher dose and longer duration of exposure led to an improved effect. Thus, a lower amount of docetaxel associated with liposomes will be required to achieve the same effect as docetaxel solution alone, which is anticipated to reduce the side effects of docetaxel. The greater antiproliferative effect was attributed mainly to a higher intracellular drug level as a result of folate-mediated phagocytosis or reduced exocytosis involving a xenobiotic extrusion pump, or both..$^{35,36} \mathrm{The}^{\mathrm{IC}_{50}}$ of FA-PDCT10000-L was significantly higher than that of FA-PDCT2000-L and FA-PDCT4000-L, which could be explained by overfolding

Table 2 Characteristics of FA-PDCT-L and FA-PCOU-L

\begin{tabular}{|c|c|c|c|c|c|}
\hline Liposome type & $\begin{array}{l}\text { Mean particle size } \\
(\mathrm{nm})\end{array}$ & $\begin{array}{l}\text { Polydispersity } \\
\text { index }\end{array}$ & EE (\%) & $\begin{array}{l}\text { Zeta potential } \\
(\mathrm{mv})\end{array}$ & $\begin{array}{l}\text { FALT } \\
(\mathrm{nm})\end{array}$ \\
\hline DCT-L & $123.7 \pm 12.8$ & $0.19 \pm 0.04$ & $97.6 \pm 1.4$ & $-32.15 \pm 1.5$ & $0.40 \pm 0.05$ \\
\hline FA-PDCT2000-L & $126.9 \pm 10.2$ & $0.20 \pm 0.03$ & $97.7 \pm 1.1$ & $-14.13 \pm 0.8^{*}$ & $3.48 \pm 0.03 *$ \\
\hline FA-PDCT4000-L & $111.6 \pm 9.6$ & $0.17 \pm 0.04$ & $97.8 \pm 1.6$ & $-11.87 \pm 2.1^{*}$ & $3.97 \pm 0.09 *$ \\
\hline FA-PDCTI0000-L & $119.7 \pm 11.4$ & $0.18 \pm 0.05$ & $97.6 \pm 1.3$ & $-6.54 \pm 1.0 *$ & $5.61 \pm 0.07^{*}$ \\
\hline COU-L & $118 \pm 10.5$ & $0.18 \pm 0.03$ & $99.9 \pm 0.8$ & $-34.5 I \pm 2.1$ & $0.43 \pm 0.06$ \\
\hline FA-PCOU4000-L & $113 \pm 9.1$ & $0.16 \pm 0.04$ & $99.8 \pm 0.7$ & $-10.62 \pm 1.8$ & $4.10 \pm 0.08$ \\
\hline
\end{tabular}

Note: Values are mean $\pm S D(n=3) . * P<0.05$ vs DCT-L. 


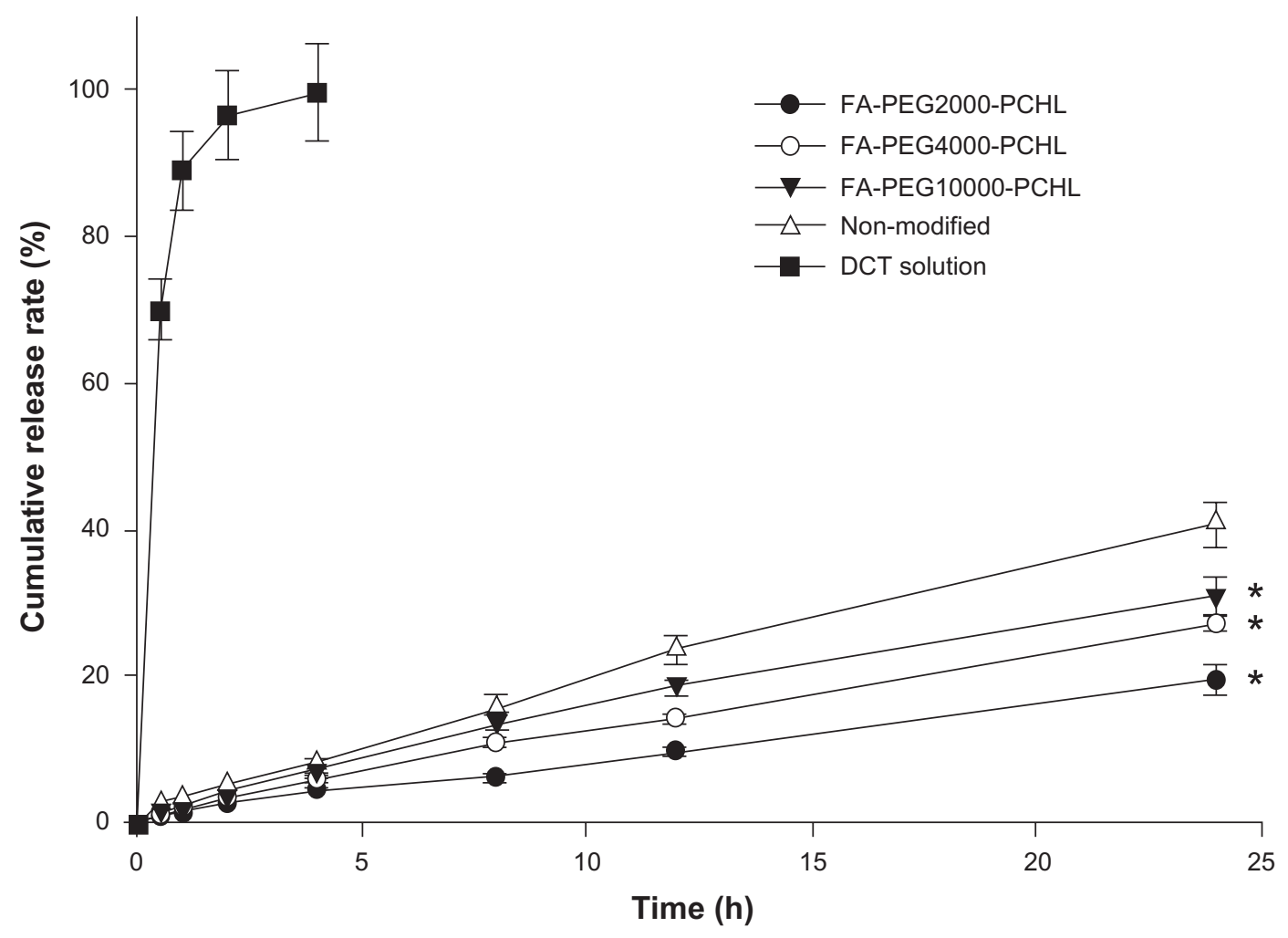

Figure 7 Release profiles of DCT from liposomes in vitro. Note: Values are mean $\pm S D(n=3)$. $* P<0.05$ vs DCT-L.

of the PEG10000 chain blocking folate, which is the key to mediation of phagocytosis for PEGylated liposomes.

\section{In vitro cellular uptake of liposomes}

To investigate folate-mediated cellular uptake, a short-term particle endocytosis test was carried out visually using coumarin-6 solution, COU-L, and FA-PCOU4000-L. To have a reliable means of comparison, the physiochemical characteristics of COU-L are shown in Table 2, and there was no significant difference between the drug-loaded liposomes and COU-L $(P>0.05)$. Figure 8 shows that COU-L (green fluorescent dots) penetrated the cells and was mostly distributed in the cytoplasm around the nucleus. Furthermore, the green fluorescent dots in samples incubated with FAPCOU4000-L were more concentrated than those incubated with coumarin-6 solution and COU-L. These images demonstrate the improved effect of folate on cellular uptake, which could be a possible explanation for the higher cytotoxicity of the FA-PEG-PCHL-modified liposomes.

\section{Acridine orange/ethidium bromide staining}

To investigate the enhanced effect of FA-PEG-PCHL on induction of apoptosis by the docetaxel-loaded liposomes,
MCF-7 cells were stained after treatment with acridine orange/ ethidium bromide, which combines the differential uptake of fluorescent DNA binding dyes, acridine orange, and ethidium bromide, allowing distinction between viable, apoptotic, and necrotic cells. Figure 9 shows late apoptotic cells (yellow stain) and necrotic cells (red stain) when exposed to docetaxel solution, docetaxel-loaded liposomes, and FA-PDCT4000-L. When treated with FA-PDCT4000-L, the number of apoptotic and necrotic cells was significantly increased, which confirmed the results for cytotoxicity of the liposomes.

\section{Annexin V/propidium iodide double staining}

Flow cytometric analysis with annexin $\mathrm{V}$ and propidium iodide staining was performed to detect apoptosis by targeting the loss of phospholipid asymmetry in the plasma membrane. MCF-7 cells were analyzed by flow cytometry after staining of phosphatidylserine translocation with FITC-annexin V in combination with propidium iodide. Phosphatidylserine is a lipid found on the inner surface of the cell membrane. When undergoing apoptosis, cells externalize phosphatidylserine, which can then be labeled with fluorochrome-conjugated annexin V. The MCF-7 cells were divided into four groups, ie, mechanically injured cells (left upper part, annexin 

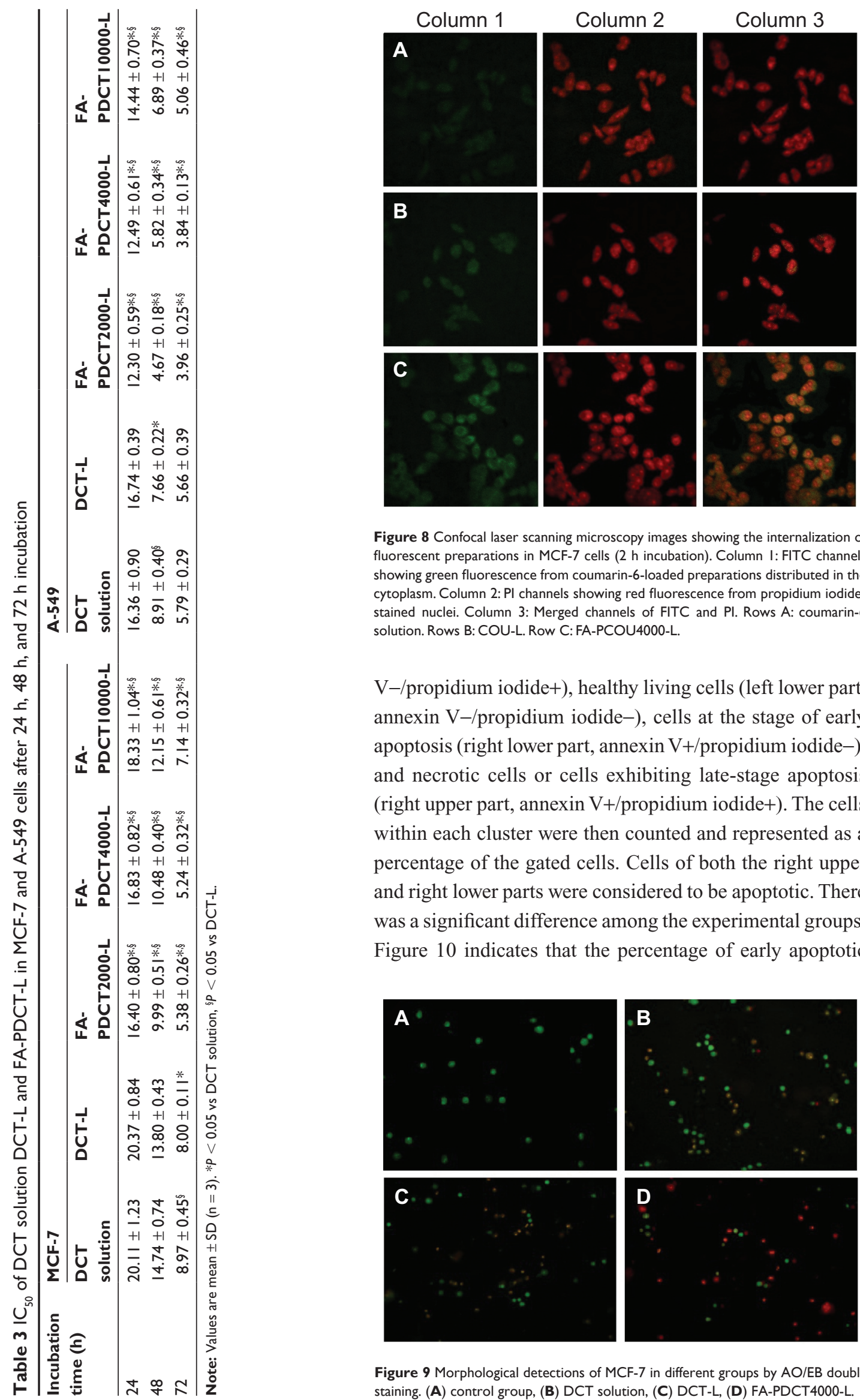

Figure 8 Confocal laser scanning microscopy images showing the internalization of fluorescent preparations in MCF-7 cells ( $2 \mathrm{~h}$ incubation). Column I: FITC channels showing green fluorescence from coumarin-6-loaded preparations distributed in the cytoplasm. Column 2: PI channels showing red fluorescence from propidium iodidestained nuclei. Column 3: Merged channels of FITC and PI. Rows A: coumarin-6 solution. Rows B: COU-L. Row C: FA-PCOU4000-L.

$\mathrm{V}-$ /propidium iodide+), healthy living cells (left lower part, annexin $\mathrm{V}-$-propidium iodide-), cells at the stage of early apoptosis (right lower part, annexin $\mathrm{V}+$ /propidium iodide-), and necrotic cells or cells exhibiting late-stage apoptosis (right upper part, annexin $\mathrm{V}+$ /propidium iodide+). The cells within each cluster were then counted and represented as a percentage of the gated cells. Cells of both the right upper and right lower parts were considered to be apoptotic. There was a significant difference among the experimental groups. Figure 10 indicates that the percentage of early apoptotic
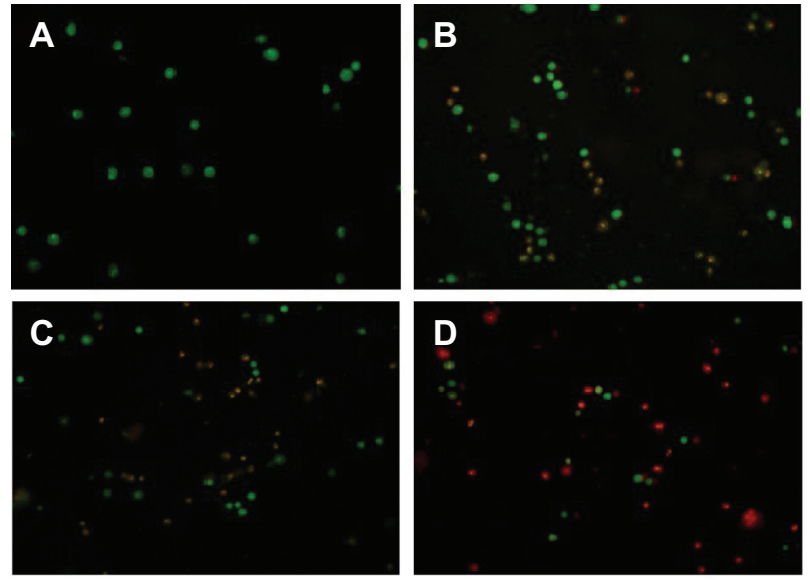

Figure 9 Morphological detections of MCF-7 in different groups by AO/EB double staining. (A) control group, (B) DCT solution, (C) DCT-L, (D) FA-PDCT4000-L. 
A

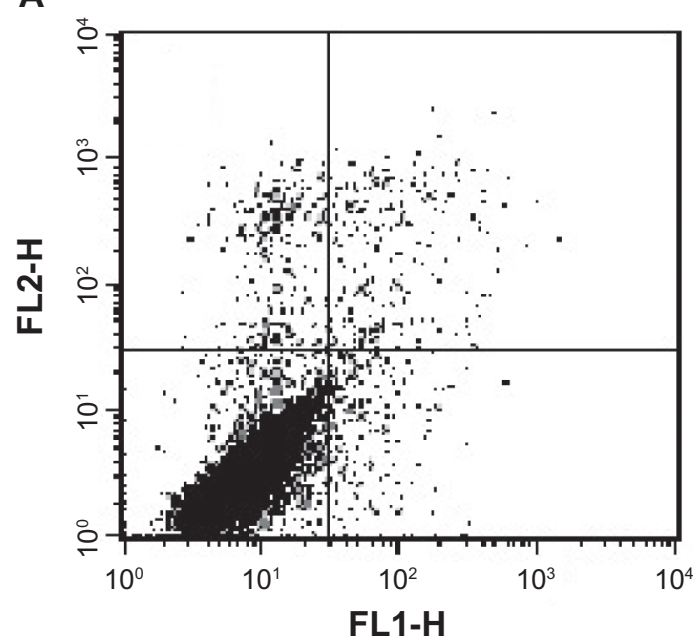

C

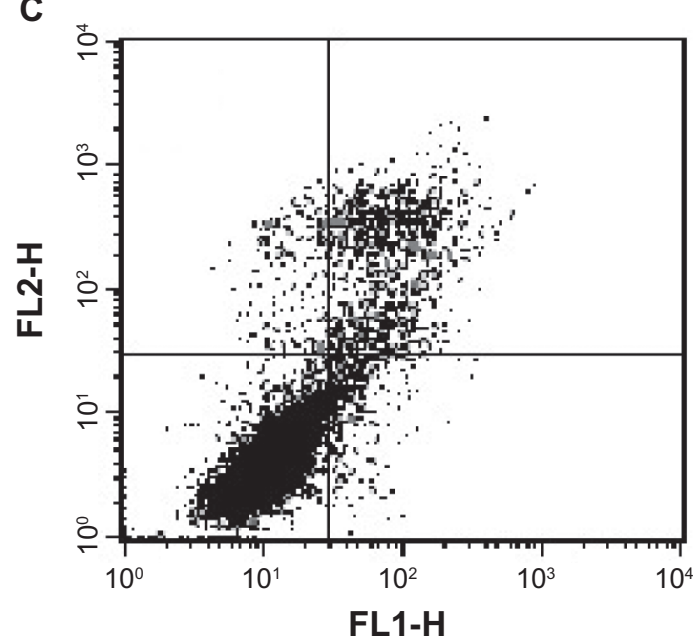

B

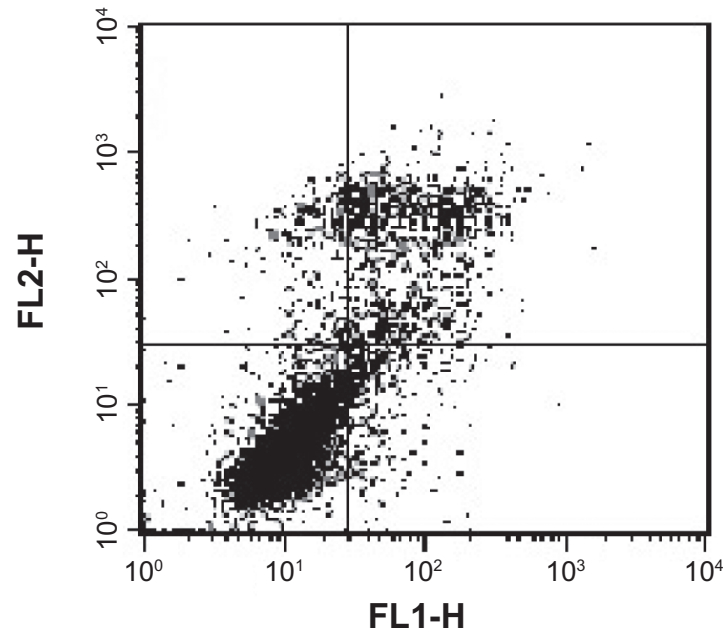

D

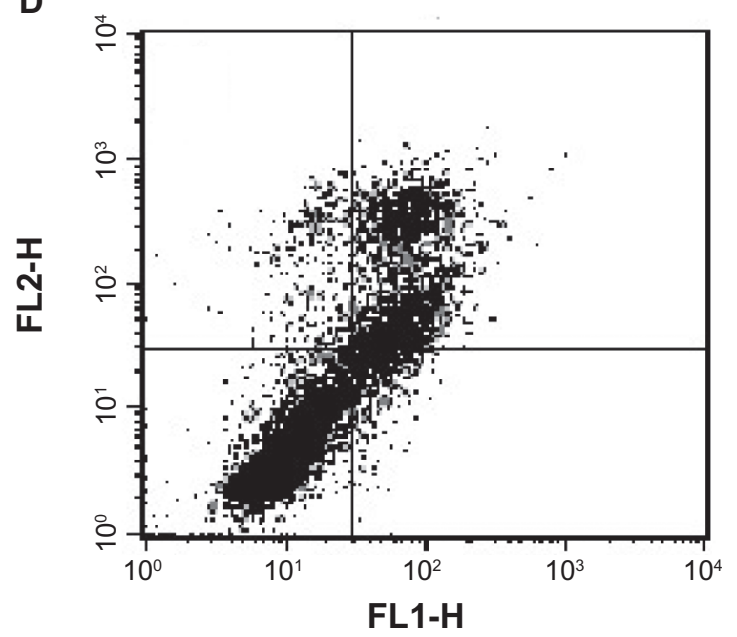

Figure 10 Dual parameter flow cytometry analysis of MCF-7 cells with annexin V/PI staining. A) control group, B) DCT solution, C) DCT-L, D) FA-PDCT4000-L.

cells and late apoptosis cells in the control group were $2.29 \%$ and $2.58 \%$, while that of the FA-PDCT4000-L group were $5.60 \%$ and $23.09 \%$, which were significantly higher than for both the docetaxel solution group (3.91\% and $11.46 \%)$ and the docetaxel-loaded liposomes group (4.50\% and $12.01 \%)$, thus showing a significant increase in apoptosis.

\section{Pharmacokinetics}

The results of the characterization analysis and in vitro cytotoxicity assays for the docetaxel preparations suggest that FA-PDCT4000-L has a better potential for tumor targeting. The research reported by Gref et al also suggest that a PEG chain with a molecular weight around 5000 Da possesses a better and longer circulation effect, and that a PEG content in the nanoparticles above $5 \%(\mathrm{w} / \mathrm{w})$ could build a good steric barrier for optimal protein resistance. ${ }^{37}$ Our work is consistent with this report. Therefore, we focused on FA-PDCT4000-L for a pharmacokinetic and tissue distribution study.
The plasma concentration-time curves for the docetaxel preparations after intravenous administration are shown in Figure 11, and the pharmacokinetic parameters are listed in Table 4. The pharmacokinetic profiles for docetaxel showed significant differences for FA-PDCT4000-L-modified liposomes versus docetaxel-loaded liposomes and docetaxel solution. In the docetaxel solution group, disappearance of docetaxel from the blood circulation was very rapid, with plasma concentrations of only $63 \mathrm{ng} / \mathrm{mL}$ at six hours. In contrast, docetaxel in the polymer-modified liposomes was still present in the circulation at 12 hours. Encapsulation of docetaxel into liposomes leads to a significant change in pharmacokinetic parameters. In vitro drug-release studies indicate that docetaxel is released slowly from the liposomes for at least 24 hours, whereas free docetaxel is not readily distributed, which explains the higher initial plasma drug concentrations for docetaxel-loaded liposomes and FA-PDCT4000-L than those for docetaxel solution. As shown in Table 4, the AUC for FA-PDCT4000-L increased 


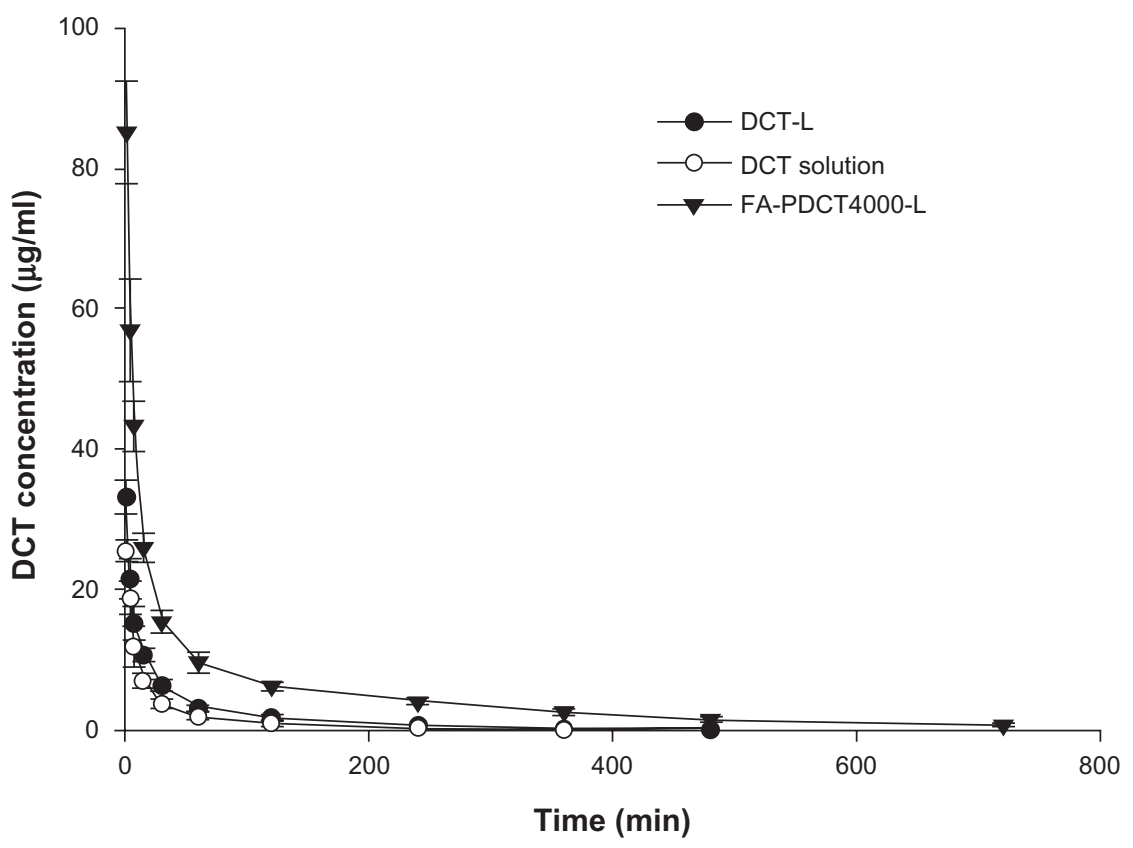

Figure I I Plasma concentrations of DCT in three preparations after intravenous administration to rats at a dose of $10 \mathrm{mg} / \mathrm{kg}$. Values are means \pm SD ( $\mathrm{n}=6$ ).

6.2-fold and 3.8-fold, while the mean residence time increased 3.3-fold and 2.5-fold compared with the docetaxel solution and docetaxel-loaded liposomes, respectively, with a corresponding decrease in clearance. This effect might be attributed to two factors. First, the negative zeta potential is key to the recognition of nanoparticles by macrophages in the mononuclear phagocyte system. Therefore, a less negative or even neutral zeta potential is expected to be necessary to avoid the macrophage system. As shown in Table 2, the reduction of negative zeta potential could be observed in FA-PDCT4000-L in contrast with the docetaxelloaded liposomes. Second, FALT is an important factor for improving liposome stability and preventing opsonization and macrophage uptake. The FALT of the FA-PDCT4000-L was thicker than that of docetaxel-loaded liposomes.

\section{Tissue distribution in sarcoma- 180 solid tumor-bearing mice}

Sarcoma-180 solid tumor-bearing mice were selected as the animal model for our biodistribution study. The distribution profiles for docetaxel solution and liposomes in S180 tumor-bearing mice at seven, 120, and 240 minutes after intravenous administration are shown in Figure 12. The drug levels in tumor for FA-PDCT4000-L were significantly higher than for the other preparations at seven minutes after administration, and were approximately 0.6 -fold and 3.1-fold greater than that for docetaxel solution and docetaxel-loaded liposomes, respectively. At 120 and 240 minutes after dosing, the docetaxel concentration from FA-PDCT4000-L in tumor remained higher in comparison with the other preparations and tissues. In addition, at 120 and 240 minutes after dosing, the tissue distribution of FA-PDCT-L was, in ranked order: tumor $>$ kidney $>$ lung $>$ spleen $>$ liver $>$ heart and brain $(P<0.05)$. There were no significant differences in docetaxel concentrations for the three formulations in brain and heart tissues at any time point $(P>0.05)$. The higher concentration of docetaxel found in kidney tumor cells in FA-PDCT4000-Ltreated mice could be explained by the folate receptor effect. Folate receptor levels are naturally rich in the kidney and are overexpressed in tumor tissues. ${ }^{38}$ The clearance behavior and tissue distribution of intravenously injected particulate drug

Table 4 Pharmacokinetic parameters of DCT in three preparations after intravenous administration to rats at a dose of $10 \mathrm{mg} / \mathrm{kg}$

\begin{tabular}{lccr}
\hline & DCT solution & DCT-L & FA-PDCT4000-L \\
\hline AUC $\left(\mu \mathrm{g} \cdot \mathrm{mL}^{-1} \cdot \mathrm{min}^{-1}\right)$ & $576.89 \pm 37.71$ & $940.07 \pm 101.47^{*}$ & $3593.55 \pm 185.89 *, 8$ \\
C $_{\max }\left(\mu \mathrm{g} \cdot \mathrm{mL}^{-1}\right)$ & $25.49 \pm 1.66$ & $33.22 \pm 3.55^{*}$ & $85.18 \pm 4.39 *, 8$ \\
Clearance $\left(\mathrm{mL} \cdot \mathrm{min}^{-1}\right)$ & $3.48 \pm 0.23$ & $2.14 \pm 0.24^{*}$ & $0.56 \pm 0.03 *, 8$ \\
MRT $(\min )$ & $60.95 \pm 0.44$ & $80.09 \pm 0.32^{*}$ & $199.48 \pm 0.2 I^{*, 8}$ \\
\hline
\end{tabular}

Note: Values are means $\pm S D(n=6) . * P<0.05$ vs DCT solution; $\$ P<0.05$ vs DCT-L. 


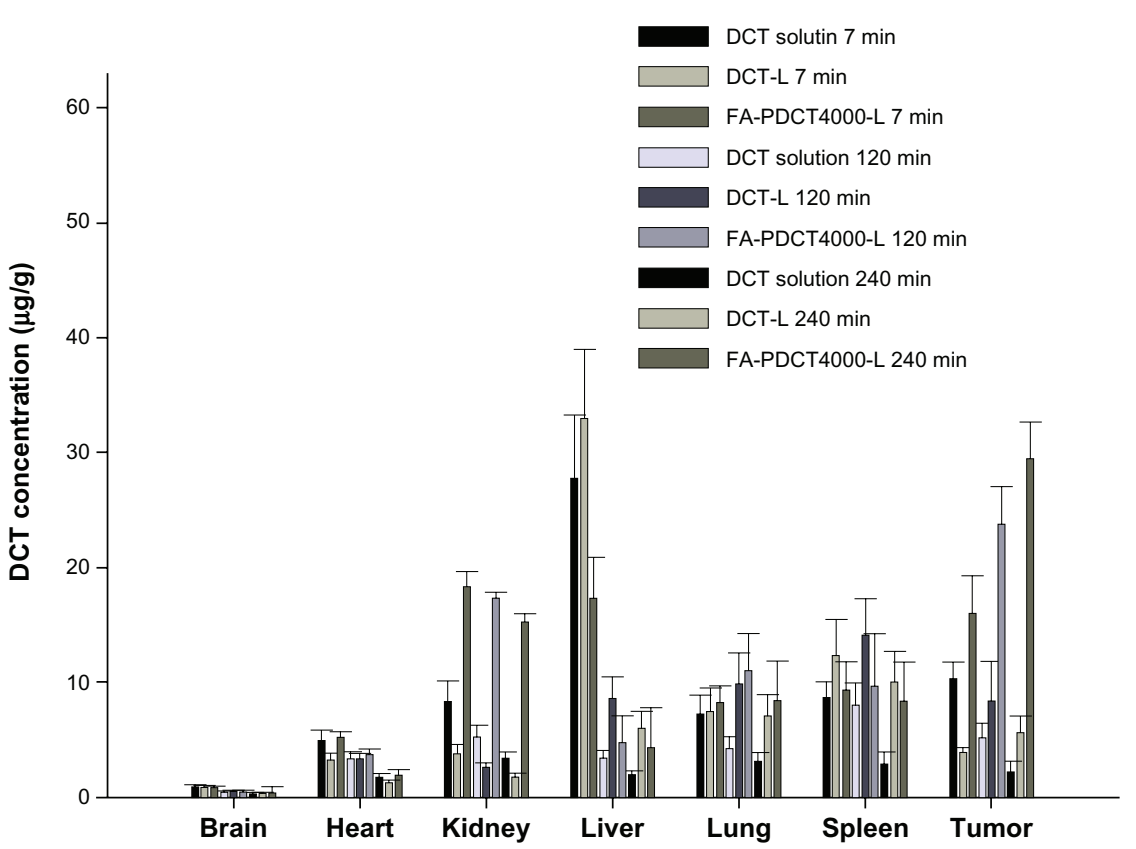

Figure 12 Tissue distribution of DCT in three preparations at different time points after intravenous administration to tumor bearing mice at a dose of $20 \mathrm{mg} / \mathrm{kg}$. Value are means \pm SD $(n=3)$.

carriers are greatly influenced by their size, surface features, and opsonization. Opsonins are adsorbed on the nanoparticle surface and promote particle recognition by the reticuloendothelial system. ${ }^{39,40}$ Lipid emulsions are rapidly taken up by the reticuloendothelial system in the liver and spleen after intravenous administration. ${ }^{41}$ The presence of a long hydrophilic chain in PEG around the shell of FA-PDCT4000-L would lead to a longer retention time in the circulation. As a result, the docetaxel concentration in liver and spleen tissue in the FA-PDCT4000-L-treated group was significantly lower than that for docetaxel-loaded liposomes. Rich blood flow with high capillary permeability could be the reason for the accumulation in lungs. The uptake of modified liposomes by the brain was not improved because of lack of the folate receptor in the inner side walls of brain capillaries. ${ }^{42}$

\section{Conclusion}

A novel polymer, ie, (FA-PEG-PCHL), with a low molecular weight and polydispersity index was successfully synthesized and used to modify docetaxel-loaded liposomes. FA-PDCT-L displayed a sustained release profile, promoted cell cytotoxicity, had a stronger apoptotic effect, prolonged the systemic circulation time, and achieved higher accumulation in tumoral tissue, thus enhancing the therapeutic action of the loading drug. Therefore, the novel polymer FA-PEGPCHL and its application in liposomal formulations could be a promising solution for delivery of antitumor drugs to cancerous tissue.

\section{Acknowledgment}

This research is supported by grants from the Natural Science Fund of Hebei Province and China Shijiazhuang Pharmaceutical Group Co Ltd. (No. C2011319007).

\section{Disclosure}

The authors report no conflicts of interest in this work.

\section{References}

1. Farokhzad OC, Langer R. Impact of nanotechnology on drug delivery. ACS Nano. 2009;3(1):16-20.

2. Cho K, Wang X, Nie SM, Chen Z, Shin DM. Therapeutic nanoparticles for drug delivery in cancer. Clin Cancer Res. 2008;14(5):1310-1316.

3. Liu YT, Li K, Pan J, Liu B, Feng SS. Folic acid conjugated nanoparticles of mixed lipid monolayer shell and biodegradable polymer core for targeted delivery of docetaxel. Biomaterials. 2010;31(2): 330-338.

4. Zhang L, Gu FX, Chan JM, Wang AZ, Langer RS, Farokhzad OC. Nanoparticles in medicine: Therapeutic applications and developments. Clin Pharmacol Ther. 2008;83(5):761-769.

5. Pulkkinen M, Pikkarainen J, Wirth T, et al. Three-step tumor targeting of paclitaxel using biotinylated PLA-PEG nanoparticles and avidin-biotin technology: Formulation development and in vitro anticancer activity. Eur J Pharm Biopharm. 2008;70(1):66-74.

6. Farokhzad OC, Cheng JJ, Teply BA, et al. Targeted nanoparticle-aptamer bioconjugates for cancer chemotherapy in vivo. Proc Natl Acad Sci U SA. 2006;103(16):6315-6320.

7. Li YP, Pei YY, Zhang XY, et al. PEGylated PLGA nanoparticles as protein carriers: Synthesis, preparation and biodistribution in rats. J Control Rel. 2001;71(2):203-211.

8. Zhao L, Wei YM, Zhong XD, et al. PK and tissue distribution of docetaxel in rabbits after i.v. administration of liposomal and injectable formulations. J Pharm Biomed Anal. 2009;49(4):989-996.

9. Wang SL, Zhang J, Jiang TY, et al. Protective effect of coenzyme $Q_{10}$ against oxidative damage in human lens epithelial cells by novel ocular drug carriers. Int J Pharm. 2011;403(1-2):219-229. 
10. Leamon CP, Low PS. Delivery of macromolecules into living cells: A method that exploits folate receptor endocytosis. Proc Natl Acad Sci US A. 1991;88(13):5572-5576.

11. Lee RJ, Low PS. Folate-mediated tumor cell targeting of liposomeentrapped doxorubicin in vitro. Biochim Biophys Acta. 1995;1233(2): 134-144.

12. Lee E, Kim H, Lee IH, Jon S. In vivo antitumor effects of chitosanconjugated docetaxel after oral administration. J Control Rel. 2009;140(2):79-85.

13. Lee RJ, Low PS. Delivery of liposomes into cultured KB cells via folate receptor-mediated endocytosis. J Biol Chem. 1994;269(5): 3198-3204.

14. Wong JY, Kuhl TL, Israelachvili JN, Mullah N, Zalipsky S. Direct measurement of a tethered ligand-receptor interaction potential. Science. 1997;275(5301):820-822.

15. Zhao XB, Muthusamy N, Byrd JC, Lee RJ. Cholesterol as a bilayer anchor for PEGylation and targeting ligand in folate-receptor-targeted liposomes. J Pharm Sci. 2007;96(9):2424-2435.

16. Chern CS, Chiu HC. Synthesis and characterization of amphiphilic graft copolymers with poly(ethylene glycol) and cholesterol side chains. Polym Int. 2004;53(4):420-429.

17. Nishikawa T, Akiyoshi K, Sunamoto J. Supramolecular assembly between nanoparticles of hydrophobized polysaccharide and soluble protein complexation between the self-aggregate of cholesterolbearing pullulan and a-chymotrypsin. Macromolecules. 1994; 27(26):7654-7659.

18. Peracchia MT, Desmaële D, Couvreur P, d'Angelo J. Synthesis of a novel poly(MePEG cyanoacrylate-co-alkyl cyanoacrylate) amphiphilic copolymer for nanoparticle technology. Macromolecules. 1997;30(4): 846-851.

19. Stella B, Arpicco S, Peracchia MT, et al. Design of folic acidconjugated nanoparticles for drug targeting. J Pharm Sci. 2000;89(11): 1452-1464.

20. Yoo HS, Park TG. Folate receptor targeted biodegradable polymeric doxorubicin micelles. J Control Rel. 2004;96(2):273-283.

21. Guo W, Lee T, Sudimack J, Lee RJ. Receptor-specific delivery of liposomes via folate-peg-chol. J Liposome Res. 2000;10(2-3):179-195.

22. Zhang MB, Lu YZ, Li XX, et al. Studying the cytotoxicity and oxidative stress induced by two kinds of bentonite particles on human B lymphoblast cells in vitro. Chem Biol Interact. 2010;183(3):390-396.

23. Zhang J, Wang SL. Topical use of coenzyme $\mathrm{Q}_{10}$-loaded liposomes coated with trimethyl chitosan: Tolerance, precorneal retention and anti-cataract effect. Int J Pharm. 2009;372(1-2):66-75.

24. Sadzuka Y, Nakade A, Hirama R, et al. Effects of mixed polyethyleneglycol modification on fixed aqueous layer thickness and antitumor activity of doxorubicin containing liposome. Int J Pharm. 2002; 238(1-2):171-180.

25. Li X, Wang DK, Zhang J, Pan WS. Preparation and pharmacokinetics of docetaxel based on nanostructured lipid carriers. J Pharm Pharmacol. 2009;61(11):1485-1492.

26. Li X, He XL, Zhao CH, Wang DK, Chen Y, Wang YH. Determination of the content and entrapment efficiency of docetaxel in nano-structured lipid carrier. China Pharm. 2008;19(22):1743-1745.
27. Yoo HS, Park TG. Biodegradable polymeric micelles composed of doxorubicin conjugated PLGA-PEG block copolymer. J Control Rel. 2001;70(1-2):63-70.

28. Pan J, Feng SS. Targeted delivery of paclitaxel using folate-decorated poly(lactide)-vitamin E TPGS nanoparticles. Biomaterials. 2008; 29(17):2663-2672.

29. Mi Y, Liu YT, Feng SS. Formulation of docetaxel by folic acidconjugated d- $\alpha$-tocopheryl polyethylene glycol succinate 2000 (Vitamin E TPGS $_{2 \mathrm{k}}$ ) micelles for targeted and synergistic chemotherapy. Biomaterials. 2011;32(16):4058-4066.

30. Lenaerts V, Couvreur P, Christiaens-Leyh D, et al. Degradation of poly (isobutyl cyanoacrylate) nanoparticles. Biomaterials. 1984; 5(2):65-68.

31. Vansnick L, Couvreur P, Christiaens-Leyh D, Roland M. Molecular weights of free and drug-loaded nanoparticles. Pharm Res. 1985; 2(1):36-41.

32. Mukherjee B, Patra B, Layek B, Mukherjee A. Sustained release of acyclovir from nano-liposomes and nano-niosomes: An in vitro study. Int J Nanomed. 2007;2(2):213-225

33. Needham D, Stoicheva N, Zhelev DV. Exchange of monooleoylphosphatidylcholine as monomer and micelle with membranes containing poly(ethylene glycol)-lipid. Biophys J. 1997;73(5):2615-2629.

34. Sulkowski WW, Pentak D, Nowak K, Sułkowska A. The influence of temperature, cholesterol content and $\mathrm{pH}$ on liposome stability. $J \mathrm{Mol}$ Struct. 2005;(744-747):737-747.

35. Wang S, Low PS. Folate-mediated targeting of antineoplastic drugs, imaging agents, and nucleic acids to cancer cells. J Control Rel. 1998; 53(1-3):39-48

36. Fabbri F, Brigliadori G, Carloni S, et al. Docetaxel-ST1481 sequence exerts a potent cytotoxic activity on hormone-resistant prostate cancer cells by reducing drug resistance-related gene expression. Prostate. 2010;70(2):219-227.

37. Gref R, Lück M, Quellec P, et al. "Stealth" corona-core nanoparticles surface modified by polyethylene glycol (PEG): Influences of the corona (PEG chain length and surface density) and of the core composition on phagocytic uptake and plasma protein adsorption. Colloids Surf B Biointerfaces. 2000;18(3-4):301-313.

38. Wu M. Expression of folate receptor type alpha in relation to cell type, malignancy, and differentiation in ovary, uterus, and cervix. Cancer Epidemiol Biomarkers Prev. 1999;8(9):775-782.

39. Moghimi SM, Hunter AC, Murray JC. Long-circulating and targetspecific nanoparticles: Theory to practice. Pharmacol Rev. 2001; 53(2):283-318

40. Manjunath K, Venkateswarlu V. Pharmacokinetics, tissue distribution and bioavailability of clozapine solid lipid nanoparticles after intravenous and intraduodenal administration. J Control Rel. 2005; 107(2):215-228.

41. Jia LJ, Zhang DR, Li ZY, et al. Nanostructured lipid carriers for parenteral delivery of silybin: Biodistribution and pharmacokinetic studies. Colloids Surf B Biointerfaces. 2010;80(2):213-218.

42. Kennedy MD, Jallad KN, Lu J, Low PS, Ben-Amotz D. Evaluation of folate conjugate uptake and transport by the choroid plexus of mice. Pharm Res. 2003;20(5):714-719.
International Journal of Nanomedicine

\section{Publish your work in this journal}

The International Journal of Nanomedicine is an international, peerreviewed journal focusing on the application of nanotechnology in diagnostics, therapeutics, and drug delivery systems throughout the biomedical field. This journal is indexed on PubMed Central, MedLine, CAS, SciSearch $\AA$, Current Contents ${ }^{\circledR} /$ Clinical Medicine,

\section{Dovepress}

Journal Citation Reports/Science Edition, EMBase, Scopus and the Elsevier Bibliographic databases. The manuscript management system is completely online and includes a very quick and fair peer-review system, which is all easy to use. Visit http://www.dovepress.com/ testimonials.php to read real quotes from published authors. 